\title{
Recent Insights into the Management of Inflammation in Asthma
}

\author{
Hitasha Rupani' \\ Wei Chern Gavin Fong ${ }^{2,3}$ \\ Aref Kyyaly iD ${ }^{2,3}$ \\ Ramesh J Kurukulaaratchy (D) ${ }^{1-4}$ \\ 'Department of Respiratory Medicine, \\ University Hospitals Southampton NHS \\ Foundation Trust, Southampton, UK; \\ ${ }^{2}$ Clinical and Experimental Sciences, \\ University of Southampton, \\ Southampton, UK; ${ }^{3}$ David Hide Asthma \\ and Allergy Research Centre, Isle of \\ Wight NHS Trust, Isle of Wight, UK; \\ ${ }^{4} \mathrm{NIHR}$ Biomedical Research Centre, \\ University Hospitals Southampton NHS \\ Foundation Trust, Southampton, UK
}

\begin{abstract}
The present prevailing inflammatory paradigm in asthma is of T2-high inflammation orchestrated by key inflammatory cells like Type 2 helper lymphocytes, innate lymphoid cells group 2 and associated cytokines. Eosinophils are key components of this T2 inflammatory pathway and have become key therapeutic targets. Real-world evidence on the predominant T2high nature of severe asthma is emerging. Various inflammatory biomarkers have been adopted in clinical practice to aid asthma characterization including airway measures such as bronchoscopic biopsy and lavage, induced sputum analysis, and fractional exhaled nitric oxide. Blood measures like eosinophil counts have also gained widespread usage and multicomponent algorithms combining different parameters are now appearing. There is also growing interest in potential future biomarkers including exhaled volatile organic compounds, micro RNAs and urinary biomarkers. Additionally, there is a growing realisation that asthma is a heterogeneous state with numerous phenotypes and associated treatable traits. These may show particular inflammatory patterns and merit-specific management approaches that could improve asthma patient outcomes. Inhaled corticosteroids (ICS) remain the mainstay of asthma management but their use earlier in the course of disease is being advocated. Recent evidence suggests potential roles for ICS in combination with long-acting beta-agonists (LABA) for as needed use in mild asthma whilst maintenance and reliever therapy regimes have gained widespread acceptance. Other anti-inflammatory strategies including ultra-fine particle ICS, leukotriene receptor antagonists and macrolide antibiotics may show efficacy in particular phenotypes too. Monoclonal antibody biologic therapies have recently entered clinical practice with significant impacts on asthma outcomes. Understanding of the efficacy and use of those agents is becoming clearer with a growing body of real-world evidence as is their potential applicability to other treatable comorbid traits. In conclusion, the evolving understanding of T2 driven inflammation alongside a treatable traits disease model is enhancing therapeutic approaches to address inflammation in asthma.
\end{abstract}

Keywords: asthma, biologics, monitoring, respiratory disease, T2 inflammation, treatable traits

\section{Introduction}

Asthma is one of the commonest chronic conditions in the world affecting over 300 million individuals worldwide, with prevalence rates ranging from $1 \%$ to $16 \%$ in different countries. ${ }^{1}$ It is rarely fatal, but the economic burden associated with asthma is extensive due to direct and indirect medical costs, including prescription drug costs, healthcare utilisation and productivity losses. Asthma is a heterogeneous disease usually characterised by chronic airway inflammation, ${ }^{1}$ bronchial hyperresponsiveness and recurrent episodes of reversible airway obstruction. Airway inflammation is a hallmark of asthma and underscores many of the
Correspondence: Ramesh J Kurukulaaratchy Clinical Experimental Sciences, University of Southampton, Southampton, UK

Tel +44 2381205232

Email R.J.Kurukulaaratchy@soton.ac.uk

Wei Chern Gavin Fong

Clinical and Experimental Sciences,

University of Southampton, Southampton UK

Tel +44 238I 205232

Email W.C.Fong@soton.ac.uk 
pathophysiological changes seen within the asthmatic airways resulting in the characteristic symptoms of asthma, such as wheeze, shortness of breath, chest tightness and cough.

Asthma management guidelines are based on a stepwise approach with treatment progressively increased to achieve asthma symptom control and reduce risk of exacerbations, with the option to reduce treatment doses after a period of symptom control. While asthma is recognised as comprising various disease subtypes, it is now frequently categorised into type 2 high (T2-high) and type 2 low (T2-low) asthma based on the predominance of cytokines and their cellular sources. Most asthma treatments target inflammatory pathways within the lung to help improve symptoms, reduce risk of exacerbations and avoid long-term complications. However, it is increasingly recognised that other treatable traits overlap with asthma and can contribute to poor symptom control in asthma.

In this review, we highlight advances in managing inflammation in asthma through the lens of the T2 paradigm alongside other relevant emerging concepts such as the "Treatable Traits" model for more complex asthma. We will review new perspectives on conventional treatments, evolving monitoring processes and current, plus potential future, higher-level biologic treatments with a focus on real-world data and clinical applicability.

\section{The Present-Day T2 Paradigm of Inflammation in Asthma}

Asthma is a heterogeneous chronic inflammatory airway disease comprising numerous phenotypes (observable clinical characteristics) and their underlying endotypes (biological pathways). The asthma disease model has evolved considerably since Rackemann first described "intrinsic" and "extrinsic" disease forms over 70-years ago. ${ }^{2}$ Morrow Brown's findings in the 1950's that sputum eosinophilia determined response to oral and inhaled corticosteroids further focused attention on the role of eosinophils in asthma pathophysiology. ${ }^{3}$ With time, associations between airway eosinophilia and more severe airway remodelling changes plus worse clinical outcomes became evident. ${ }^{4}$ Thereafter evolved the concept of "T2-high" and "T2low" asthma inflammatory endotypes ${ }^{5}$ defined by the presence or absence of Type 2 (T2) inflammatory processes. T2 inflammation may be orchestrated by either (CD4+) Type 2 helper (Th2) lymphocytes or innate lymphoid cells group 2 (ILC2). ${ }^{6}$ Th2 lymphocytes elaborate cytokines that have critical "asthma-genic" actions including interleukin (IL)-4, IL-5 and IL-13. IL-4 promotes production of $\operatorname{IgE}$ from B lymphocytes, increases expression of lowaffinity $\mathrm{CD} 23$ ( $\left.\mathrm{F}_{\mathrm{C} \varepsilon} \mathrm{RII}\right) \mathrm{IgE}$ receptors on $\mathrm{B}$ lymphocytes and macrophages while directing class switching of naïve CD4 T-helper lymphocytes to the T2 type. ${ }^{7}$ IL-13 shares a common receptor (IL-4R $\alpha$ ) with IL-4 and shows similar effects including promoting IgE production and CD23 expression. $^{8,9}$ IL-4 and IL-13 also induce goblet cell metaplasia and MUC5AC production, favouring mucus production in the asthmatic airway. ${ }^{9}$ IL-5 is a key driver of eosinophilic processes, responsible for eosinophil migration into the asthmatic airway where they are a predominant cell type in $\mathrm{T} 2$ disease. $^{10}$ Eosinophils therefore remain a prime target for a range of evolving asthma treatment options from newer inhaled corticosteroids and other prophylactic medications to monoclonal antibody biologic treatments. In parallel, blood eosinophil count (BEC) has gained widespread acceptance as a surrogate of airway pathophysiology. Conversely, non-eosinophilic and non-T2 phenotypes potentially less responsive to conventional and higher-level biologic treatments have been described too. ${ }^{11}$ However, defining non-T2 asthma largely by the absence of $\mathrm{T} 2$ features potentially leaves room for misclassification. For instance, it is known that BEC show considerable temporal variability and alongside other T2 markers such as Fractional Exhaled Nitric Oxide (FeNO) are susceptible to numerous modifying factors including treatments. $^{12}$ Neutrophilic airway inflammatory profiles have long been linked to severe asthma and may constitute a proportion of non-T2 asthma. ${ }^{13}$ They can be facilitated by IL-17 mediated pathways which have also been linked to severe asthma. ${ }^{14,15}$ Paucigranulocytic (low) airway inflammatory profiles may comprise a further proportion of non-T2 asthma. ${ }^{16}$ Systemic inflammation in association with metabolic dysfunction and obesity has also been linked to non-T2 asthma. ${ }^{17}$

How does the T2 paradigm relate to asthma encountered in clinical practice? The Global Initiative for the management of Asthma (GINA) proposed a multidimensional algorithm to define $\mathrm{T} 2$ status - any of $\mathrm{BEC} \geq 150$ cells $/ \mu \mathrm{L}$, sputum eosinophilia $\geq 2 \%$, FeNO $\geq 20 \mathrm{ppb}$, clinically allergy-driven asthma, or on maintenance oral corticosteroids for asthma. ${ }^{18}$ GINA estimated that $50 \%$ of severe asthma is T2 in nature. ${ }^{19}$ In line with that estimate, recent data from UK-SAR (the United Kingdom Severe Asthma Registry) classified $45 \%$ of subjects as T2 when that was defined as both $\mathrm{BEC} \geq 150$ cells $/ \mu \mathrm{L}$ and $\mathrm{FeNO} \geq$ 
$25 \mathrm{ppb}^{20}$ However, emerging real-world data using broader perspectives suggests a greater extent of $\mathrm{T} 2$ status among patients with severe asthma.

Heaney et al recently reported findings within ISAR, the International Severe Asthma Registry ${ }^{21}$ using data on 1716 patients from 11 national registries. They applied a consensus-driven eosinophil gradient algorithm to assess eosinophilic phenotypes in severe asthma classifying eosinophilic status from Grade 3 (most likely eosinophilic), Grade 2 (likely eosinophilic), Grade 1 (least likely eosinophilic) to Grade 0 (non-eosinophilic). The variables selected to inform the algorithm were: highest BEC ever ( $\geq 300, \geq 150-300,<150$ cells $/ \mu \mathrm{L}$ ), anti-IL-5/IL-5R (eosinophil targeting) biologic treatment, long-term oral corticosteroid ever (m-OCS), elevated FeNO ever ( $\geq 25 \mathrm{ppb})$, nasal polyps diagnosis ever, and adult-onset asthma $(\geq 18$ years). Non-eosinophilic status was defined as highest BEC ever $<150$ cells $/ \mu \mathrm{L}$ without nasal polyps, elevated FeNO, adult-onset asthma or m-OCS. Conversely, Grade 3 (most eosinophilic likelihood) was defined as either highest $\mathrm{BEC}$ ever $\geq 300$ cells/ $\mu \mathrm{L}$ OR anti-IL-5/IL-5R therapy, OR with $\mathrm{BEC} \geq 150-300$ cells $/ \mu \mathrm{L}$ on (i) m-OCS or (ii) with $\geq 2$ of nasal polyps, elevated FeNO or adult-onset disease. Using this approach, eosinophilic phenotypes heavily predominated in severe asthma with $83.8 \%$ of subjects falling into "most likely" eosinophil phenotypes and only $1.6 \%$ falling into non-eosinophil phenotypes. Supporting evidence for such levels of eosinophilic/T2 disease comes from recently published UK data from the Wessex AsThma CoHort of difficult asthma (WATCH) study. $^{22}$ That real-world study used historical electronic health records to longitudinally study blood eosinophil status in difficult asthma patients over a 10 -year period. It found that while $40.3 \%$ showed $\mathrm{BEC} \geq 300$ cells $/ \mu \mathrm{L}$ at WATCH enrolment, this proportion rose to $83.4 \%$ when viewed longitudinally. Furthermore, if the BEC cut-off was dropped to $\geq 200$ cells $/ \mu \mathrm{L}$, the prevalence of "eosinophilia ever" rose to $96.6 \%$.

How do eosinophilic and non-eosinophilic severe asthma phenotypes differ in core characteristics and clinical outcomes? Most severe asthma cohorts show female predominance. ${ }^{21,23-25}$ While ISAR confirmed that, it showed proportionately greater prevalence of male sex in the eosinophilic than in the non-eosinophilic group. ${ }^{21}$ The eosinophil group were both older and had older age of asthma onset echoing recent identification in the WATCH study of a hitherto less acknowledged adult-onset eosinophilic male difficult asthma phenotype. ${ }^{23}$ The ISAR study found no significant difference in numerous asthma characteristics including severity between eosinophilic and non-eosinophilic phenotypes. ${ }^{21}$

Collectively, these real-world studies suggest exercising caution before designating non-eosinophilic severe asthma status. Eosinophil-phenotype predominance in severe asthma highlights that most severe asthma patients fall within the remit of T2-biologics such as Omalizumab, Mepolizumab, Reslizumab, Benralizumab and Dupilumab which are transforming treatment options for many patients with asthma. It is though important to recognise that some patients don't respond to T2-biologics as recently shown by real-world studies like WATCH. ${ }^{26}$ Understanding the mechanisms behind such failed responses will be a matter for future research focus.

\section{Biomarkers That Support Asthma Management}

The diagnosis and management of asthma is generally based on a combination of reported symptoms and lung function tests that assess reversible airway obstruction and airway hyperresponsiveness (AHR). However, these do not directly reflect underlying airway inflammation and cannot discriminate different phenotypes. Therefore, biomarkers that can reflect airway inflammation are needed to guide diagnosis, help accurately identify clinically relevant phenotypes, guide treatment decisions and potentially also inform prognosis. In this section, we present an overview of asthma biomarkers and discuss their advantages plus barriers to their implementation. We have focused on adults with asthma but similar biomarkers are used in the paediatric population. The advantages and disadvantages of currently used clinical biomarkers are summarized in Figure 1.

\section{Airway Sampling Though Bronchoscopy}

Bronchial biopsy, obtained through fiberoptic bronchoscopy, was first used for research purposes in asthma in 1977. ${ }^{27}$ Since then, many have considered bronchial biopsy the "gold standard" for investigating airway inflammation because it enables detailed study of the epithelium, basement membrane and submucosa, allows quantification of inflammatory cells and permits evaluation of their activation status. Bronchial biopsies from patients with asthma often show epithelial shedding, goblet cell hyperplasia, thickened lamina reticularis, increased inflammatory cells (especially eosinophils) and basement membrane thickening, a hallmark of airway remodelling. ${ }^{28,29}$ Bronchial 


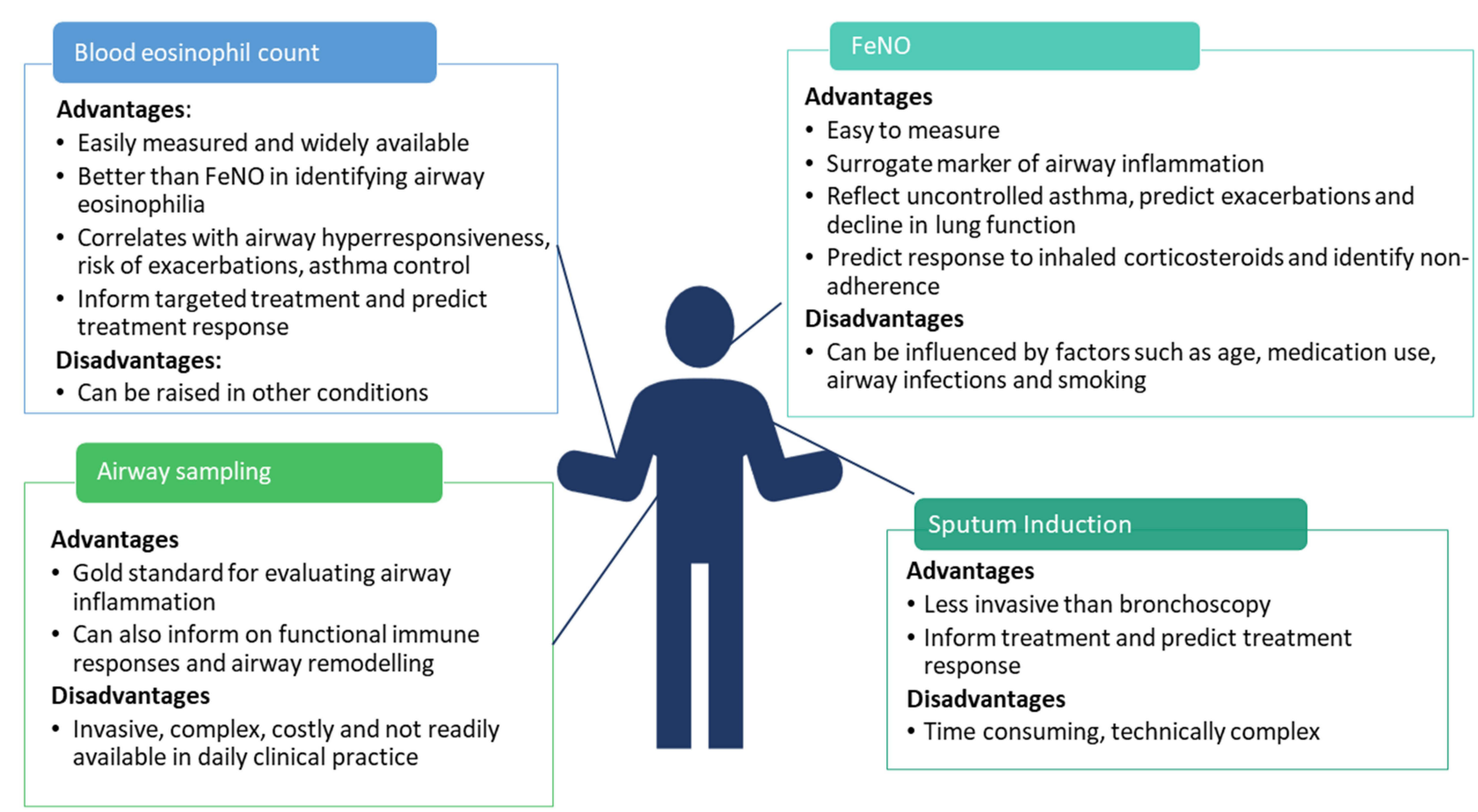

Figure I Advantages and disadvantages of commonly used asthma biomarkers. Abbreviation: FeNO, fractional exhaled nitric oxide.

brushings, also obtained through bronchoscopy provide bronchial epithelial cells which can be harvested and cultured in vitro. Bronchial epithelial cells are key producers of inflammatory and immune mediators and these in vitro studies have greatly advanced our understanding of the inflammatory and immune responses within the asthmatic airway. Finally, bronchoalveolar lavage, performed during bronchoscopy, allows for analysis of inflammatory cells, cytokines and other soluble mediators from the distal airways. However, while bronchoscopy has contributed significantly to the enhanced understanding of asthma, it is invasive, complex, costly to perform, not readily available in daily clinical practice and therefore remains mainly a research tool.

\section{Sputum Induction}

Sputum induction is less invasive and more-cost-effective than bronchoscopy but remains time-consuming, technically complex and requires specialist resource, preventing its widespread use in routine clinical practice. Four inflammatory phenotypes have been identified based on analysis of sputum: eosinophilic, neutrophilic, mixed and paucigranulocytic. ${ }^{30}$ The number of eosinophils in sputum from asthmatic patients is significantly raised compared with healthy people and correlates with severe exacerbations and AHR. ${ }^{31}$ Sputum eosinophil guided treatment of patients with moderate to severe asthma is associated with fewer severe asthma exacerbations and fewer hospital admissions compared to management based on symptoms and clinical assessment alone. ${ }^{32}$ Using sputum eosinophilia to guide asthma medication cannot be extended to children due to the lack of sufficient data. ${ }^{33}$

Studying sputum inflammometry in patients with severe asthma has been a focus for many years. The Severe Asthma Research Program III (SARP III) recently reported data from 206 subjects with severe asthma that shows the majority $(59 \%)$ have low eosinophils $(<2 \%)$ in sputum. Similarly, in the Wessex Severe Asthma Cohort, the majority of the 210 participants $(59 \%)$ had low sputum eosinophils $(\leq 3 \%)^{34}$ albeit the cut-offs used varied slightly between the two cohorts. It is also recognised that levels of inflammatory cells in sputum vary over time and with treatment. Variable levels of sputum eosinophilia were found in $15 \%$ of patients in SARP III over a 3-year period. Such patients had the highest rate of exacerbations despite being on greater treatment, higher even than patients with persistently raised sputum eosinophilia. This highlights that fluctuation in sputum eosinophil count is more closely linked to asthma control than the absolute levels of these inflammatory cells. 


\section{Fractional Exhaled Nitric Oxide}

Nitric oxide (NO) is a gas normally found in exhaled breath and at constitutive levels has numerous regulatory and immunomodulatory roles. ${ }^{35}$ Using a hand-held analyser, the fraction of $\mathrm{NO}$ in exhaled breath $(\mathrm{FeNO})$ can be measured in a convenient, non-invasive and reproducible manner, making it a valuable clinical tool. Within the asthmatic airway, T2 cytokines upregulate the production of nitric oxide. ${ }^{36,37}$ High FeNO levels are therefore thought to be a surrogate marker of ongoing airway inflammation and may reflect uncontrolled asthma, predict asthma exacerbations ${ }^{38}$ and decline in lung function. ${ }^{39,40}$

However, the clinical usefulness of FeNO is still debated, mainly because various other factors can influence FeNO levels such as age, medication use, airway infections, smoking status and other diseases including eosinophilic bronchitis. This probably explains why studies investigating the association between FeNO and asthma control provide inconsistent results. ${ }^{41}$

FeNO $>50$ ppb can predict response to inhaled corticosteroid therapy (ICS) ${ }^{42,43}$ and in patients with a diagnosis or suspected diagnosis of asthma, measurement of FeNO can support the decision to start ICS. Levels are also responsive to changes in $\mathrm{ICS}^{44}$ and the degree of suppression of FeNO resulting from ICS therapy has been used to identify non-adherence to this treatment in a difficult-to-treat asthma population. ${ }^{45}$ However, outside of this group of patients, the evidence is low and therefore the National Asthma Education and Prevention Coordinating Committee (NAEPPCC) 2021 recommends against the routine use of FeNO to evaluate adherence. ${ }^{44}$ While a management strategy involving FeNO guided treatment adjustment has been shown to be associated with a significantly reduced exacerbation risk (OR $0.60 ; 95 \%$ CI $0.43-0.84$ in adults and OR 0.58 ; $95 \%$ CI $0.45-0.75$ in children) in a recent meta-analysis, ${ }^{46}$ international guidelines are cautious with their recommendations. GINA advises against FeNO-guided adjustment to asthma treatment while the NAEPPCC makes a conditional recommendation that $\mathrm{FeNO}$ can be used in conjunction with usual clinical parameters including history, clinical findings and spirometry. ${ }^{1,44}$

FeNO can modestly predict airway eosinophilia with a recent meta-analysis suggesting an area under the receiver operator curve (AUROC) for detecting sputum eosinophils $\geq 3 \%$ of 0.75 (95\% CI $0.72-0.78)$, sensitivity of $66 \%$ (95\% CI $57-75 \%)$ and specificity of $76 \%(95 \%$ CI $65-85 \%) .{ }^{47}$ However, clinical experience with FeNO has shown that while T2-inflammation and airway eosinophilia may overlap, they are not synonymous. This distinction has been clearly demonstrated with the use of anti-IL5 (Mepolizumab) and anti-IL4R $\alpha$ (Dupilumab) monoclonal antibodies. Mepolizumab use leads to significant reductions in peripheral blood eosinophil levels without any change in FeNO while Dupilumab reduces FeNO without affecting blood eosinophil levels. ${ }^{48,49}$

\section{Biomarkers in Blood Blood Eosinophil Count}

BEC is easily measured and widely available, with the added advantage that patients often have a standard full blood count checked for various reasons and therefore a recent (or historical) BEC is usually available. They reflect inflammation in the asthmatic airway and are better than FeNO in the identification of sputum eosinophilia in asthma (AUROC for BEC 0.89 while for FeNO 0.78). ${ }^{50}$ Eosinophils correlates with AHR and rate of decline in $\mathrm{FEV}_{1}$ in younger and older adults, independent of the presence of asthma. ${ }^{51,52}$ They are useful in the early detection of exacerbations. Large intervention studies in patients with mild, moderate and severe asthma show that the BEC is independently associated with up to a fivefold increased risk for severe exacerbations. ${ }^{48,53,54}$ They correlate with asthma control ${ }^{55}$ and can inform targeted treatment and predict treatment response, especially to asthma biologics in adults and children. ${ }^{48,49,56,57}$ However, the utility of BEC is limited by low overall specificity for eosinophilic airway inflammation $^{58}$ as raised BEC can be seen in other autoimmune diseases, atopic diseases and parasitic infections.

\section{Serum Periostin}

Periostin is a matricellular protein secreted by bronchial epithelial cells and fibroblasts under the influence of IL-13. ${ }^{59}$ Gene expression studies show that it is amongst the most highly expressed genes in the T2 high population ${ }^{5}$ and it is considered a biomarker of T2, IL-13 driven steroid-responsive asthma. ${ }^{60}$ However, correlation between serum periostin and sputum eosinophilia is inconsistent. While the BOBCAT study showed it was predictive of eosinophilic airway inflammation with an AUROC of $0.84,{ }^{61}$ in another study, periostin was unable to distinguish eosinophilic asthma from non-eosinophilic asthma. ${ }^{50}$ However, the use of this biomarker is limited by the lack of well-established and validated cut-off values and standardised measurement techniques that can be employed in routine clinical care. 
Periostin levels can change with age and affected by bone growth and turnover - this is particularly relevant in children. Therefore, the usefulness of serum periostin in children is still debated and largely due to inconsistencies in results.

\section{Combining Biomarkers}

Combining FeNO levels with BEC may add additional discriminatory value in predicting exacerbations and response to treatment. Price et al demonstrated that primary care patients with FeNO $>50 \mathrm{ppb}$ and $\mathrm{BEC}>300$ cells $/ \mu \mathrm{L}$ were almost four times as likely to have a severe exacerbation compared to biomarker low patients. ${ }^{43}$ Recently, a group in Oxford have proposed the ORACLE score (Oxford Asthma attaCk risk scaLE) which can predict asthma attacks based on these two biomarkers combined with concurrent risk factors including poor symptom control, low lung function, adherence issues and reliever overuse. ${ }^{62}$ Combined biomarker high patients also respond better to certain, but not all, biologic treatments ${ }^{48}$ highlighting the heterogeneity in airway inflammation in asthma. As described above, recently, the ISAR proposed an algorithm to predict an eosinophilic phenotype based on BEC and FeNO combined with select clinical characteristic highlighting the benefit of combining clinically available biomarkers. $^{21}$

\section{Future Biomarkers to Aid Management of Inflammation in Asthma}

The ideal biomarker should have good performance characteristics, such as sensitivity, specificity, positive-predictive and negative predictive values. Furthermore, it should be simple to measure and cost-effective. ${ }^{63}$ So what candidates might fit that bill for future use as asthma biomarkers? It is beyond the scope of this Review to undertake detailed assessment of future biomarkers that could prove useful in guiding management of inflammation in asthma. Here, we briefly highlight 3 promising candidates.

\section{MicroRNAs}

MicroRNAs (miRNAs) are short, single-stranded RNA molecules, 18-22 nucleotides long and highly conserved throughout evolution ${ }^{64}$ that have been associated with particular asthma phenotypes. ${ }^{65}$ Several studies reported correlations between miRNAs and asthma phenotypes, for example, several miRNAs have been linked to T2 asthma including miR155, miR-146a, miR-21, miR-1248, miR-210 and miR-1. ${ }^{66,67}$ Other miRNAs have been linked to neutrophilic asthma including miR-199a-5p, miR- 223-3p, miR-142-3p and miR$629-3 p .{ }^{68}$ Additionally, miR-1 level was found to be inversely correlated with asthma severity. ${ }^{67}$ Another study, showed that expression levels of miR-125b in serum exosomes were significantly different among patients with intermittent, mildly, moderately, and severely persistent asthma having a high diagnostic efficacy for asthma severity. ${ }^{69} \mathrm{~A}$ set of miRNAs were recently associated with asthma that could also classify asthmatics into two clusters by serum eosinophil numbers and periostin concentration. Some of these asthma-specific miRNAs have been identified in sera, including miR-185$5 p .{ }^{70}$ In neutrophilic asthma, miR-199a-5p, miR-223-3p, miR-142-3p and miR-629-3p were upregulated in induced sputum. miR-629-3p was expressed in bronchial epithelium and miR-223-3p and miR-142-3p - in neutrophils, monocytes and macrophages. ${ }^{66}$ Such biomarkers could therefore have a future potential to aid endotypic recognition at individual patient levels and facilitate future stratified medicines approaches.

\section{Exhaled Volatile Organic Compounds}

Exhaled volatile organic compounds (VOCs) include a wide range of potential substances such as alkanes, hydrocarbon ring structures, alcohols, aldehydes, aromatic hydrocarbons and ketones. They offer a means to noninvasively examine airway inflammatory status and phenotype in line with the concept of distinguishing treatable traits. Such "breathomic" analyses both via broad-ranging platforms such as e-Nose as well as more targeted gas chromatography-mass spectrometry have identified eosinophil and neutrophilic phenotypes of airway disease distinguished by exhaled breath constituents (such as 3,7dimethylnonane, nonanal and 1-propanol) rather than predetermined diagnostic labels. ${ }^{71,72}$ They have also demonstrated differences in exhaled VOCs such as methanol, acetonitrile, and bicyclo [2.2.2]octan-1-ol, 4-methyl between stable and uncontrolled asthma status. ${ }^{73}$ Conversely, other studies have failed to show such clear breathomic signatures. ${ }^{74}$ Further work to validate these early findings is needed but initial systematic reviews suggest promise to this potential VOC-based biomarker approach. $^{75}$

\section{Urinary Biomarkers}

Urinary biomarkers have also attracted recent interest in relation to asthma. T2 status has been associated with raised urinary metabolites of prostaglandin $\mathrm{D}_{2}$ and cysteinyl-leukotriene (LT) $\mathrm{E}_{4}$ with equivalent accuracy to 
conventional markers. ${ }^{76}$ Urinary $\mathrm{LTE}_{4}$ has also shown potential as a marker for AERD. ${ }^{77}$ Conversely, an IL-17 high asthma phenotype has been associated with elevated urinary degradation products of thromboxane B2 that might serve as a biomarker for future attempts at IL-17 targeted therapy. ${ }^{78}$ Urinary bromotyrosine in combination with FeNO was also found to best predict clinical inhaled corticosteroid response. ${ }^{79}$ Urinary biomarker guided asthma management is therefore likely to be an area of growing research focus.

\section{The Treatable Traits Paradigm - Difficult-to-Control Asthma as a Multimorbidity Difficult Breathing Syndrome}

Our current pharmacotherapeutic approach to asthma is moulded to the T2 paradigm. Yet clinical studies show wide heterogeneity to asthma both across the life course and at different levels of asthma severity. ${ }^{25,80-82}$

It is also clear that a proportion of patients with asthma do not attain good asthma control with current treatments. This failure to deliver good asthma control with current approaches was the focus of a Lancet 2017 Commission "After asthma: redefining airways disease". ${ }^{83}$ In addition, the realisation is dawning that asthma seldom occurs as an isolated health problem. In particular at the more "difficultto-control" end of the spectrum asthma often constitutes part of a multimorbidity constellation of conditions best regarded as a "Difficult Breathing Syndrome" rather than "Severe Asthma" alone. An important new taxonomic approach to airways disease based on identifying and managing component factors rather than generic disease labels such as asthma was recently proposed by Agusti. ${ }^{84}$ Such potentially modifiable factors, known as "treatable traits" may be broadly categorised as pulmonary, extrapulmonary and behavioural in nature and occur concurrently in combinations that are specific to the individual patient. A core tenet of this framework is to acknowledge the underlying biological complexity of clinical presentations in a manner that facilitates more precise asthma management that is more personalised and holistic (Table 1). That shifts thinking away from the "one approach suits all" attitude encouraged by traditional guideline-based management.

Treatable traits are common in difficult-to-treat, asthma where they may cluster to a greater degree in individual patients. ${ }^{85-88}$ Of note, the burden of treatable traits appears to align with worse asthma outcomes such as exacerbations, asthma control and quality of life. ${ }^{85,87,88}$ A systematic clinical approach to addressing treatable traits in asthma has recently shown clinical effectiveness. ${ }^{89}$ So how can addressing specific treatable traits impact airway inflammation in asthma and asthma outcomes? A broad overview of treatable traits in asthma is provided in Table 1. Selected examples are further discussed below while specific treatments are assessed in subsequent sections of this Review.

\section{Pulmonary Traits}

\section{Airway Inflammatory Phenotypes}

Airway eosinophilia is defined by elevated sputum eosinophils $(\geq 2 \%)$ or surrogate markers such as FeNO $(\geq 25 \mathrm{ppb}) .{ }^{18}$ Although conventionally responsive to inhaled and/or oral corticosteroids, eosinophilic asthma phenotypes may prove more difficult-to-treat and have emerged as dominant in the severe asthma population. ${ }^{21,22}$ Patients who do not respond to conventional therapies should have multi-disciplinary team input including management of any comorbidities and optimisation of adherence and inhaler technique before resorting to higher-level biologic strategies. It is worth noting that the evolution of anti-IL5 therapy itself demonstrated the value of a treatable traits approach. When first assessed clinically without stratification by eosinophil phenotype it showed limited efficacy, ${ }^{90}$ only to demonstrate clinical impact when trialled in patients with clear eosinophilic status. ${ }^{91,92}$ Neutrophilic airway inflammation is variably defined by sputum neutrophils $(\geq 40 \%$ or $\geq 61 \%$ ) and has been linked to asthma severity through worse lung function, relative corticosteroid resistance and high healthcare utilisation. ${ }^{13,93-95}$ It may be associated with smoking, pollutants and repeated infections which merit attention as associated treatable traits. ${ }^{96-98}$ Macrolide antibiotics offer potential anti-inflammatory treatment for this phenotype. ${ }^{99}$ Mixed inflammatory airways disease is characterised by dual eosinophil and neutrophilic airway inflammation and may show worse lung function and asthma outcomes including exacerbations and healthcare utilisation. ${ }^{99,100}$ Conversely, paucigranulocytic airway disease is characterized by a combination of low sputum eosinophils and neutrophils. In some cases, this may reflect the effect of treatments on airway inflammatory profiles and has been linked to less severe disease status. ${ }^{16,101}$ No bespoke treatment exists for paucigranulocytic airways disease but there is speculation that long-acting bronchodilators and bronchial thermoplasty may offer some utility. ${ }^{102}$ While airway inflammatory status is a key treatable trait, the longitudinal stability of such asthma endotypes remains unconfirmed. ${ }^{103}$ Both treatment 
Table I Treatable Traits in Asthma; Evaluation and Management Options

\begin{tabular}{|c|c|c|c|}
\hline & Trait & Diagnostic Evaluation & Management Options \\
\hline \multirow[t]{10}{*}{ Pulmonary } & Airflow Limitation & Spirometry with $\mathrm{FEV}_{\mathrm{I}} / \mathrm{FVC}<0.7$ & $\begin{array}{l}\text { Inhaled corticosteroids, long acting } \beta 2 \text { agonists, long-acting } \\
\text { antimuscarinic agents. }\end{array}$ \\
\hline & Small Airways Disease & $\begin{array}{l}\text { Impaired } \mathrm{FEF}_{25-75} \text {, impaired } \\
\text { oscillometry, evidence of air-trapping } \\
\text { on plethysmography } \pm \mathrm{HRCT} \text {. }\end{array}$ & Ultrafine particle inhaled corticosteroids. \\
\hline & $\begin{array}{l}\text { Airway Inflammatory } \\
\text { Phenotype (Eosinophilic, Mixed) }\end{array}$ & $\begin{array}{l}\text { Sputum eosinophils (\%), blood } \\
\text { eosinophil count, FeNO }\end{array}$ & $\begin{array}{l}\text { Inhaled corticosteroids, leukotriene antagonists, oral } \\
\text { corticosteroids, monoclonal antibody therapies. }\end{array}$ \\
\hline & $\begin{array}{l}\text { Airway Inflammatory } \\
\text { Phenotype (Neutrophilic) }\end{array}$ & Sputum neutrophils (\%) & $\begin{array}{l}\text { ?Long-acting antimuscarinic agents, ?prophylactic antibiotics, ? } \\
\text { bronchial thermoplasty. }\end{array}$ \\
\hline & $\begin{array}{l}\text { Airway Inflammatory } \\
\text { Phenotype (Paucigranulocytic) }\end{array}$ & Sputum eosinophils and neutrophils (\%) & $\begin{array}{l}\text { ?Long-acting antimuscarinic agents, ?prophylactic antibiotics, ? } \\
\text { bronchial thermoplasty. }\end{array}$ \\
\hline & Allergic Fungal Airway Disease & $\begin{array}{l}\text { Total lgE, specific IgE to Aspergillus, } \\
\text { Aspergillus Precipitins, HRCT chest. }\end{array}$ & $\begin{array}{l}\text { Inhaled/ oral corticosteroids, antifungal agents, monoclonal } \\
\text { antibody therapies. }\end{array}$ \\
\hline & $\begin{array}{l}\text { Aspirin Exacerbated } \\
\text { Respiratory Disease }\end{array}$ & $\begin{array}{l}\text { Clinical history \& examination, aspirin } \\
\text { challenge }\end{array}$ & $\begin{array}{l}\text { Aspirin desensitisation, salicylate lowering diet, inhaled } \\
\text { corticosteroids, leukotriene antagonists, oral corticosteroids, } \\
\text { monoclonal antibody therapies. }\end{array}$ \\
\hline & $\begin{array}{l}\text { Airway Infections } \pm \\
\text { Colonisation }\end{array}$ & $\begin{array}{l}\text { Clinical history, antibiotic history, } \\
\text { sputum culture. }\end{array}$ & Acute/ prophylactic antibiotics. \\
\hline & Bronchiectasis & $\begin{array}{l}\text { Clinical history \& examination, HRCT, } \\
\text { sputum culture. }\end{array}$ & Chest clearance, prophylactic antibiotics, nebulised antibiotics \\
\hline & Dual COPD & $\begin{array}{l}\text { Clinical history \& examination, } \\
\text { spirometry, transfer factors, HRCT, } \\
\text { sputum culture. }\end{array}$ & $\begin{array}{l}\text { Smoking cessation, chest clearance, pulmonary rehabilitation, } \\
\text { long acting } \beta 2 \text { agonists, long-acting antimuscarinic agents. }\end{array}$ \\
\hline \multirow[t]{10}{*}{$\begin{array}{l}\text { Extra- } \\
\text { Pulmonary }\end{array}$} & Rhinitis & Clinical history \& examination, & $\begin{array}{l}\text { Topical nasal steroids, antihistamines, leukotriene antagonists, } \\
\text { nasal rinses, allergen immunotherapy. }\end{array}$ \\
\hline & $\begin{array}{l}\text { Chronic Rhinosinusitis ( } \pm \text { Nasal } \\
\text { Polyps) }\end{array}$ & $\begin{array}{l}\text { Clinical history \& examination, } \\
\text { nasendoscopy, CT sinuses. }\end{array}$ & Topical nasal steroids, antibiotics, nasal rinses, surgery. \\
\hline & $\begin{array}{l}\text { Gastro-Oesophageal Reflux } \\
\text { Disease }\end{array}$ & $\begin{array}{l}\text { Clinical history \& examination, upper } \\
\mathrm{Gl} \text { endoscopy, } \mathrm{pH} \text { monitoring. }\end{array}$ & Proton pump inhibitors, $\mathrm{H} 2$ antagonists, weight loss, surgery. \\
\hline & Obesity & Body Mass Index & Diet, exercise, medication, bariatric surgery. \\
\hline & Deconditioning & Clinical history, 6 Minute Walk Test & Exercise. \\
\hline & Obstructive Sleep Apnoea & $\begin{array}{l}\text { Clinical history \& examination, Epworth } \\
\text { Sleepiness Score, sleep study. }\end{array}$ & $\begin{array}{l}\text { Weight loss, mandibular advancement devices, Continuous } \\
\text { Positive Airways Pressure therapy. }\end{array}$ \\
\hline & Dysfunctional Breathing & $\begin{array}{l}\text { Clinical history \& examination, } \\
\text { Nijmegen score. }\end{array}$ & Physiotherapy support. \\
\hline & $\begin{array}{l}\text { Intermittent Laryngeal } \\
\text { Dysfunction }\end{array}$ & $\begin{array}{l}\text { Clinical history \& examination, indirect } \\
\text { laryngoscopy. }\end{array}$ & Speech therapy support. \\
\hline & Depression & $\begin{array}{l}\text { Clinical history \& examination, HADS } \\
\text { score. }\end{array}$ & Psychologist support. \\
\hline & Anxiety & $\begin{array}{l}\text { Clinical history \& examination, HADS } \\
\text { score. }\end{array}$ & Psychologist support. \\
\hline
\end{tabular}

(Continued) 
Table I (Continued).

\begin{tabular}{|l|l|l|l|}
\hline & Trait & Diagnostic Evaluation & Management Options \\
\hline Behavioural & Smoking & $\begin{array}{l}\text { Clinical history, exhaled carbon } \\
\text { monoxide, urinary cotinine. }\end{array}$ & Smoking cessation support, nicotine replacement therapy. \\
\cline { 2 - 4 } & Adherence & $\begin{array}{l}\text { Clinical history, prescription pick up } \\
\text { data, "smart inhalers", prednisolone } \\
\text { assay. }\end{array}$ & $\begin{array}{l}\text { Patient education, motivational interviewing, self-management } \\
\text { guidance. }\end{array}$ \\
\cline { 2 - 5 } & Poor Inhaler Technique & Direct assessment. & Patient education. \\
\cline { 2 - 5 } & Distorted Symptom Perception & $\begin{array}{l}\text { Comparison of objective and subjective } \\
\text { measures. }\end{array}$ & $\begin{array}{l}\text { Patient education, treatment of relevant psychophysiologic } \\
\text { traits. }\end{array}$ \\
\hline
\end{tabular}

Abbreviations: $\mathrm{FEV} / \mathrm{FVC}$, forced expiratory volume in I second/ forced vital capacity ratio; $\mathrm{FEF}_{25-75}$, mid-expiratory flow; HRCT, High-Resolution $\mathrm{CT}$; FeNO, fractional exhaled nitric oxide; COPD, Chronic Obstructive Pulmonary Disease; CT Sinus, Computed Tomography Sinus; GI, Gastrointestinal; HADS, Hospital Anxiety and Depression Score.

(corticosteroid escalation or weaning) plus external factors like smoking and infection might influence inflammatory phenotype status at single timepoints signalling the need to consider re-evaluation if clinical status changes.

\section{Allergic Bronchopulmonary Aspergillosis/ Severe Asthma with Fungal Sensitisation}

Sensitization to fungal allergens like Aspergillus fumigatus (A. fumigatus) has been associated with worse asthma severity through states like "Severe Asthma with Fungal Sensitization" (SAFS) and Allergic Bronchopulmonary Aspergillosis (ABPA). ${ }^{104,105}$ Notably, A. fumigatus sensitization has been linked to poor asthma control, higher treatment needs, greater healthcare utilization, potential mortality risk, impaired lung function and bronchiectasis. ${ }^{106-112}$ ABPA shows a specific mixed inflammatory pattern ${ }^{106,113}$ and classical cyclical pattern of exacerbation and worsening airway structural damage if untreated. ${ }^{42}$ Potential anti-inflammatory treatments include antifungal treatments, oral and inhaled corticosteroids, and consideration of higher-level biological agents. $^{114-116}$

\section{Aspirin-Exacerbated Respiratory Disease (AERD)}

Aspirin-sensitive asthma is typically adult-onset, with higher prevalence in females plus associations to chronic rhinosinusitis with nasal polyps (CRSwP) and chronic spontaneous urticaria. ${ }^{117}$ AERD is associated with baseline dysregulated arachidonic acid metabolism, heightened leukotriene responses, subdued prostaglandin E2 production and an eosinophilic phenotype. ${ }^{118,119}$ Conventional treatments including inhaled corticosteroids and leukotriene antagonists may prove useful but such patients often show progressive worsening of asthma control and increasing oral corticosteroid dependency. ${ }^{117,119}$ Adjunct treatments include aspirin desensitisation, salicylate lowering diets and nasal polypectomy. ${ }^{120-122}$ Given their underlying eosinophilic phenotype, AERD patients may benefit from T2-targeting biologic agents. ${ }^{123}$

\section{Extrapulmonary Traits}

\section{Rhinitis}

Mutually detrimental co-expression of asthma and rhinitis as a "unified airways disease" arising from homologous local inflammation plus secondary immunological messaging across upper and lower airway is well recognised. ${ }^{124,125}$ Such bidirectional severity associations may be established in childhood and potentially track along the life-course. ${ }^{126}$ Rhinitis therapy can reduce asthma symptom burden in mild asthmatics but similar impact in more severe asthma is lacking evidence. ${ }^{127}$ Potential rhinitis therapies that might impact comorbid asthma include antihistamines, nasal corticosteroids, leukotriene antagonists, nasal rinses and immunotherapy though the latter is contraindicated in poorly controlled asthma. ${ }^{128}$

\section{Chronic Rhinosinusitis (CRS)}

CRS with (CRSwP) or without nasal polyposis (CRSsNP) is strongly associated with asthma, worse asthma control and shows similar T2-based inflammatory signatures. ${ }^{129-131}$ Some CRS subjects demonstrate perpetuation of chronic inflammation via staphylococcal nasal mucosal colonisation whereby staphylococcal Enterotoxin-B acts as a superantigen to drive local IgE formation. ${ }^{132}$ Current treatments for CRSwP/ CRSsNP that might aid the patient with comorbid asthma include nasal corticosteroids, nasal rinses, antibiotics (particularly doxycycline given anti-staphylococcal coverage) and surgical polypectomy to debulk inflamed tissue while a 
potential role for monoclonal antibody therapies in CRSwP is emerging. ${ }^{133}$ CRS therapy can improve asthma control, oral corticosteroid dependency and healthcare utilisation. ${ }^{134-136}$

\section{Obesity}

Obesity is highly prevalent among difficult asthma populations $^{23,25,80}$ and is associated with worse asthma severity. ${ }^{137}$ The negative impact of obesity on asthma may be part-mediated by mechanical effects on lung function. ${ }^{138}$ Additionally, obesity may be associated with neutrophilic airway inflammation, increased adipokine expression and manifestations of systemic inflammation. ${ }^{139-142}$ IL-6 may play a significant role in subtypes of obese asthma and offer a future therapeutic target. ${ }^{17}$ Obesity-targeting measures like conventional weight loss, broader lifestyle changes and bariatric surgery have shown efficacy in improving clinical asthma outcomes and some markers of systemic and local inflammation. ${ }^{143-146}$

\section{Behavioural Traits Smoking}

Smoking remains prevalent in asthmatics and impairs response to anti-inflammatory medications like inhaled corticosteroids. $^{147,148}$ Smoking cessation can rapidly improve lung function and reduce airway neutrophilia in asthmatic patients but may require personalised and novel approaches. $^{149,150}$

\section{Adherence}

Non-adherence to asthma medication is frequent among the difficult asthma population and a significant reason for ongoing airway inflammation. ${ }^{151,152}$ Assessment of nonadherence is difficult and a single gold standard measure does not exist but traditional measures have included FeNO monitoring and prednisolone assays. ${ }^{153}$ Emerging tools include remote inhaler monitoring, remote FeNO suppression tests, using simplified dosing regimes where possible and use of interactive digital technologies. ${ }^{154-158}$

\section{Conventional Anti-Inflammatory Asthma Treatments}

Asthma is a chronic inflammatory disease of the airways and therefore anti-inflammatory treatment is the mainstay of asthma management. The aim of treatment is to reduce symptom burden (ie, good symptom control while maintaining normal activity levels) and minimise the risk of adverse events such as exacerbations, fixed airflow obstruction and treatment side effects. ${ }^{1}$ Treatment guidelines recommend a stepwise approach with progression to the next step recommended when control is not achieved or is lost at the current step. A comparative overview of three commonly used guidelines is given in Table 2 .

\section{Inhaled Corticosteroids (ICS) Therapy}

Up until recently, asthma treatment guidelines recommended as required short-acting beta-agonists (SABAs) as first-line treatment for patients with mild asthma, adopting an approach that aimed to control symptoms. If symptoms persisted, treatment was stepped up and ICS therapy was initiated. This approach stemmed from the dated idea that asthma symptoms are related to bronchoconstriction (caused by bronchial smooth muscle contraction) rather than a condition concomitantly caused by airway inflammation $^{159}$ and therefore as required SABA monotherapy (which relaxes airway smooth muscle) is sufficient in "mild" asthma when symptoms are infrequent. However, while symptoms experienced by patients with mild asthma may not be troublesome or frequent, airway inflammation is usually present. Between $30 \%$ and $40 \%$ of exacerbations requiring emergency care have been shown to occur in patients with mild asthma. ${ }^{160}$ Asthma exacerbations are associated with considerable morbidity, progressive decline in lung function and are an important predictor of future exacerbations. ${ }^{161}$ Therefore, in 2019 GINA guidelines changed to no longer recommend treatment with SABA alone, even in patients with mild asthma. $^{1}$

This change can be considered as revolutionising the management of patients with mild asthma and was based on evidence that had been available for some years. Firstly, it had been recognised that although SABAs effectively reduce symptoms, they are ineffective in treating the underlying inflammatory process. Patients treated with SABA alone are at risk of asthma-related death ${ }^{162}$ and urgent asthma-related healthcare utilisation ${ }^{163}$ - both are reduced with regular use of ICS. In fact, Suissa et al showed a clear inverse dose-dependent relationship between number of ICS canisters used in a year and the rate ratio for death from asthma. ${ }^{162}$ The benefit of using ICS at step 1/mild asthma was further reinforced in 2006 when the results of a 10-year asthma programme in Finland was published. Through a comprehensive educational programme for primary care that focused mainly on the premise that asthma is an inflammatory disease and requires anti-inflammatory treatment from the outset, the 
Table 2 Comparison of Adult Asthma Chronic Management Guidelines

\begin{tabular}{|c|c|c|c|}
\hline & Global Initiative for Asthma 202 I & $\begin{array}{c}\text { National Asthma Education and } \\
\text { Prevention Program Guidelines } \\
\text { 2021 }\end{array}$ & British Thoracic Society Guidelines 2019 \\
\hline & Non Applicable & Intermittent Asthma: PRN SABA & $\begin{array}{l}\text { Suspected Asthma: Can Consider } \\
\text { Monitored Initiation of Low Dose ICS }\end{array}$ \\
\hline “Step” I & $\begin{array}{l}\text { As-needed low dose ICS/formoterol } \\
\text { OR } \\
\text { ICS used at the same time as SABA }\end{array}$ & $\begin{array}{l}\text { Regular low dose ICS + PRN SABA } \\
\text { OR } \\
\text { ICS used at the same time as SABA }\end{array}$ & Regular low dose ICS + PRN SABA \\
\hline “Step" 2 & $\begin{array}{l}\text { As needed low dose ICS/formoterol } \\
\text { OR } \\
\text { Regular low dose ICS + PRN SABA }\end{array}$ & $\begin{array}{l}\text { Regular and as required low dose ICS/ } \\
\text { formoterol }\end{array}$ & $\begin{array}{l}\text { Regular low ICS/LABA + PRN SABA } \\
\text { OR } \\
\text { Low dose maintenance and reliever ICS/LABA }\end{array}$ \\
\hline "Step" 3 & $\begin{array}{l}\text { Low dose maintenance and reliever ICS/ } \\
\text { formoterol } \\
\text { OR } \\
\text { Low dose maintenance ICS/LABA + } \\
\text { PRN SABA }\end{array}$ & $\begin{array}{l}\text { Regular and as required medium dose } \\
\text { ICS/formoterol }\end{array}$ & $\begin{array}{l}\text { Medium dose ICS/LABA +PRN SABA } \\
\text { OR } \\
\text { Low dose ICS/LABA + LTRA +PRN SABA }\end{array}$ \\
\hline "Step" 4 & $\begin{array}{l}\text { Medium dose maintenance ICS/ } \\
\text { formoterol + as needed low dose ICS- } \\
\text { formoterol } \\
\text { OR } \\
\text { Medium/high dose maintenance ICS/ } \\
\text { LABA + PRN SABA }\end{array}$ & $\begin{array}{l}\text { Daily medium-high dose ICS/LABA + } \\
\text { LTRA or LAMA + PRN SABA } \\
\text { Consider adding asthma biologic }\end{array}$ & $\begin{array}{l}\text { Refer patient to specialist care for consideration } \\
\text { of specialist therapies (including asthma } \\
\text { biologics) }\end{array}$ \\
\hline 'Step’5 & $\begin{array}{l}\text { Add LAMA } \\
\text { Consider high dose ICS/formoterol } \\
\text { OR } \\
\text { Add on LAMA, consider high dose ICS/ } \\
\text { LABA } \\
\text { Refer for consideration of asthma } \\
\text { biologic }\end{array}$ & $\begin{array}{l}\text { Daily high-dose ICS/LABA + PRN } \\
\text { SABA + OCS } \\
\text { Consider adding asthma biologic }\end{array}$ & \\
\hline
\end{tabular}

Abbreviations: ICS, inhaled corticosteroids; SABA, short-acting beta-agonist; LABA, long-acting beta-agonist; LTRA, leukotriene receptor antagonist; OCS, oral corticosteroid; PRN, As needed.

use of ICS increased from $33 \%$ to $85 \%$ with a parallel decrease in asthma-related hospital admissions and days off work. ${ }^{164}$

However, given the low frequency of symptoms in mild asthma, patient's adherence to regular ICS is usually low. ${ }^{165-167}$ This can result in SABA overuse, especially if SABAs are available in pharmacies as non-prescription medicines. Numerous patient surveys have highlighted that inhaled treatments are more likely to be used when asthma symptoms occur and avoided in the absence of symptoms. ${ }^{168}$ Therefore, in 2019, GINA recommended as-needed low-dose ICSformoterol in Step 1. ${ }^{1}$ While this was initially an offlabel recommendation, the publication of the SYGMA 1 and SYGMA 2 trials which compared budesonide/ formoterol with as-needed terbutaline or with regular budesonide plus as-needed terbutaline, provided firm evidence base for their recommendation. ${ }^{166,169}$ Both trials showed as-needed budesonide/formoterol was similar to budesonide maintenance at preventing severe exacerbations with substantial reduction in overall ICS dose (83\% in SYGMA 1 and $75 \%$ in SYGMA 2). These results were replicated in the real-world Novel START study which confirmed non-inferiority of asneeded budesonide/formoterol compared to regular budesonide despite a $52 \%$ reduction in mean ICS dose. ${ }^{170}$ However, maintenance budesonide was superior to as-needed budesonide-formoterol for asthma symptom control, measured by the Asthma Control questionnaire-5. 
The other important advantage of as-needed low-dose ICS/LABA therapy in mild asthma is in the management of exacerbations. Patients on regular ICS or ICS plus LABA tend to rely on their SABA, which provides symptom relief but no anti-inflammatory effects. Replacing regular ICS with or without LABA with fast-acting LABA/ICS combination makes it possible to avoid SABA overuse and ensures that each time a patient takes an inhaler for symptom relief, they receive extra ICS. A recent meta-analysis has shown this approach results in a one-third reduction in risk of severe exacerbations. ${ }^{171}$

\section{ICS/LABA as Maintenance and Reliever Therapy}

It is well recognised that in the $\sim 10$ days preceding the commencement of oral steroids to treat an exacerbation, asthma symptoms and SABA use increases and this is usually accompanied by a decrease in peak expiratory flow (PEF). ${ }^{172}$ Symptomatic asthma is associated with worsening airway inflammation and therefore if an ICS is administered with the rescue bronchodilator, the patient would receive anti-inflammatory therapy when it is required, reducing symptoms and need for oral steroids. Indeed, the SMILE study in which patients with moderate to severe asthma treated with budesonide/formoterol as maintenance therapy received either SABA, formoterol or budesonide/formoterol to use as reliever therapy showed that the risk of severe exacerbation was reduced significantly with budesonide/formoterol maintenance and reliever. ${ }^{173}$ Timely increase in ICS dose achieved by using ICS/LABA as maintenance and reliever therapy is more effective than higher doses of maintenance ICS/LABA and despite using the ICS/LABA as reliever therapy, the overall ICS use is lower than in fixed-dose regimes. ${ }^{174,175}$ While GINA has endorsed this for many years, the American NAEPPCC guidelines 2021 have finally recommended ICS/LABA maintenance and reliever therapy. ${ }^{1,44}$

While there is firm consensus in all international guidelines on the role of ICS in all severities of asthma, the recent publication of the Steroids in Eosinophil Negative Asthma (SIENA) study adds some controversy. ${ }^{176}$ Lazarus et al classified patients with mild asthma according to sputum eosinophil level (sputum eosinophil high $\geq 2 \%$ or low if sputum eosinophil $<2 \%$ ). The patients were randomised to receive ICS, tiotropium or placebo with treatment response defined as a composite outcome that incorporated treatment failure, asthma control days and $\mathrm{FEV}_{1}$. The majority of patients (73\%) were found to be sputum eosinophil low and there was no significant difference in their response to either ICS or tiotropium as compared to placebo. However, In the sputum eosinophil high group, ICS performed better than tiotropium.

In summary, all patients with asthma should receive inhaled steroid therapy, with low-dose as-needed ICS/ LABA being a favourable option as it overcomes issues with poor adherence and cost-effective vs ICS and LABA as separate inhalers. We must move away from the historic distinction between so-called "intermittent" and "mild persistent" asthma as patients with few interval asthma symptoms can still have severe or fatal exacerbations. ${ }^{160}$

\section{Ultrafine-Particle Inhalers}

Technological advances in device engineering and drug formulation have led to the development of inhalers emitting small-particle or ultrafine drug-aerosol which enhances drug deposition into the lung with more effective drug penetration into the lung periphery. This was driven largely by The Montreal Protocol of 1987 which required the eventual banning of all chlorofluorocarbons (CFC), including those in metered-dose inhalers (MDI) ${ }^{177}$ Drug deposition into the lung periphery is particularly desired because airway inflammation in asthma affects the entire respiratory tract including the large, intermediate and small airways. Furthermore, many natural allergens, such as cat dander, fungal spores and pollen reach the distal airways ${ }^{178,179}$ and density of steroid receptors increases further down the airways. ${ }^{180}$ Real-world studies show that treatment with small-particle aerosols resulted in better asthma control, improved quality of life and lower ICS dose compared with large particle aerosol treatment. ${ }^{181}$ These studies have led many to question why LABAs are added as a preferential step-up therapy when simply switching to an ultra-fine particle ICS could be attempted first. While this is an option, ICS/LABA combination inhalers are preferred for the reasons discussed above.

\section{Montelukast}

Cysteinyl Leukotrienes (CysLTs) are key mediators produced by airway immune cells and their interaction with the innate immune system leads to many of the pathognomonic features of asthma including smooth muscle contraction, AHR, enhanced mucus secretion, increases vascular permeability, eosinophilic airway inflammation and airway remodelling. ${ }^{182,183}$ This recognition led to the development of CysLT receptor antagonists with 
montelukast most widely used due its efficacy and safety profile. Leukotriene synthesis and CysLT receptor expression is not inhibited by steroids, ${ }^{184,185}$ further promoting the clinical utility of montelukast. Since its approval for use over two decades ago, montelukast has become established in stepwise asthma treatment algorithms. It is able to reduce SABA requirements, improve lung function, and reduce symptoms and risk of exacerbation in adults and children with asthma. ${ }^{186,187}$ However, more recently the clinical utility of montelukast in people with asthma and specific comorbidities is becoming increasingly recognised. These groups include people with asthma and rhinitis, exercise-induced asthma, asthma and obesity, aspirin-exacerbated respiratory disease, and preschool children with asthma and wheezing disorders. ${ }^{188}$ In this era of precision medicine, the presence of these comorbidities should prompt clinicians to consider montelukast.

\section{Azithromycin}

Azithromycin is macrolide antibiotic that has antibacterial and anti-inflammatory effects. In a large randomised, doubleblind, Australian study in moderate-to-severe asthma (AMAZES), azithromycin given three times a week reduced exacerbations (incidence rate ratio $0.59,95 \%$ CI $0.47-0.74$ compared to placebo) and improved asthma-related quality of life. ${ }^{189}$ While it had been previously proposed that prophylactic macrolide therapy may be more beneficial in patients with non-eosinophilic sputum, ${ }^{190}$ in this study, Gibson et al demonstrated that it reduced exacerbations in patients with eosinophilic as well as non-eosinophilic asthma. GINA recommends that it can be considered after specialist referral for adults with uncontrolled asthma despite high-dose ICS/LABA, but not used before a specialist review due to the potential risk of population-level antibiotic resistance. ${ }^{1}$ In addition to reducing key inflammatory proteins (IL-6, IL1 $\beta$, extracellular DNA, tumour necrosis factor markers), ${ }^{191,192}$ azithromycin use is also associated with structural changes including increased airway lumen radius and area in patients with severe persistent asthma. ${ }^{193}$ Airway abundance of Haemophilus influenzae has been shown to predict a more favourable response to azithromycin ${ }^{194}$ and in our personalised approach to asthma management prospective assessment for the presence of Haemophilus influenza should be used to facilitate the identification of patients for this treatment.

\section{Allergen-Specific Immunotherapy in Asthma}

Allergen-specific immunotherapy (AIT) may be a treatment option when allergy is a prominent trigger for asthma symptoms and exacerbations. It can be delivered through two approaches: subcutaneous immunotherapy (SCIT) and sublingual immunotherapy (SLIT). The rationale behind and proposed mechanism for AIT is it modifies the underlying allergic pathways leading to allergen-specific tolerance and suppression of inflammation with clinical benefits seen in daily symptoms and exacerbations. ${ }^{195}$ House dust mites (HDM) SLIT has been shown to delay time to exacerbation during ICS reduction in adults with suboptimally controlled asthma and HDM allergic rhinitis. ${ }^{196}$ The European Academy of Allergy and Clinical Immunology recommends HDM-AIT as add-on treatment for HDM-driven allergic asthma as there is evidence it can reduce exacerbations and improve asthma control. ${ }^{197}$ However, compared to pharmacological and avoidance options, the benefits of AIT need to be weighed against the cost to the patient and health system, potential side effects and inconvenience of the prolonged course of therapy.

\section{Current Real-World Understanding of Biologics in Asthma}

Multiple biologic drugs have entered clinical practice for severe asthma in recent years following an extensive portfolio of Phase 3 trials. A common approach of these monoclonal antibodies is precision management of $\mathrm{T} 2$ inflammation albeit by targeting different treatable traits. Here, we focus on emerging real-world data for five asthma biologics approved by the European Medicines Agency, ${ }^{198-202}$ namely Omalizumab, Mepolizumab, Reslizumab, Benralizumab and Dupilumab. Appreciating the real-world experience with such medication is increasingly important as real-life severe asthma patients often do not match the clinical trial populations in which these medications showed original efficacy. ${ }^{203,204}$ Findings are summarized in Table 3 and discussed in detail below.

\section{Omalizumab}

IgE plays a key role in mediating disease severity in allergic asthma. Allergen-specific IgE binds to the highaffinity receptor (FceRI) on effector cells (mast cells, basophils) and antigen-presenting cells. Cross-linking of effector cell-bound IgE releases inflammatory mediators 
Table 3 Current Biological Treatments in Severe Asthma. Targets, Eligibility, Dosing Regimen and Real World Impact

\begin{tabular}{|c|c|c|c|c|}
\hline $\begin{array}{l}\text { Biologic } \\
\text { Name }\end{array}$ & $\begin{array}{l}\text { Molecular } \\
\text { Target }\end{array}$ & $\begin{array}{l}\text { Eligibility Criteria for Adults } \\
\text { (Based on EMA) })^{1-5}\end{array}$ & Dosing Regimen & Real World Impacts \\
\hline Omalizumab & Free $\lg \mathrm{E}$ & $\begin{array}{l}\text { As add-on therapy to improve asthma } \\
\text { control in patients with severe } \\
\text { persistent allergic asthma who have a } \\
\text { positive skin test or in vitro reactivity } \\
\text { to a perennial aeroallergen and who } \\
\text { have reduced lung function (FEVI } \\
<80 \% \text { ) as well as frequent daytime } \\
\text { symptoms or night-time awakenings } \\
\text { and who have had multiple } \\
\text { documented severe asthma } \\
\text { exacerbations despite daily high-dose } \\
\text { inhaled corticosteroids, plus a long- } \\
\text { acting inhaled beta2-agonist. }\end{array}$ & $\begin{array}{c}\text { 2-4 weekly, subcutaneously based on } \\
\text { Total IgE level and body weight }\end{array}$ & $\begin{array}{l}\text { Improvement in } \mathrm{FEV}_{1} \text {, Asthma } \\
\text { control, exacerbations, OCS } \\
\text { requirements, healthcare } \\
\text { utilisation }^{26,211,221}\end{array}$ \\
\hline Mepolizumab & IL-5 & Severe refractory eosinophilic asthma & $100 \mathrm{mg}, 4$ weekly, subcutaneously & $\begin{array}{l}\text { Improvement in asthma } \\
\text { control, exacerbations, OCS } \\
\text { requirements, healthcare } \\
\text { utilisation, AQLQ, } \\
\mathrm{FEV}_{1}{ }^{26,117,239,241,275}\end{array}$ \\
\hline Reslizumab & IL-5 & $\begin{array}{l}\text { Severe eosinophilic asthma } \\
\text { inadequately controlled despite high } \\
\text { dose inhaled corticosteroids plus } \\
\text { another medicinal product for } \\
\text { maintenance treatment. }\end{array}$ & $\begin{array}{l}3 \mathrm{mg} / \mathrm{kg} 4 \text { weekly, intravenously over } \\
20-50 \text { minutes }\end{array}$ & $\begin{array}{c}\text { Improvement in } \\
\text { exacerbations, OCS } \\
\text { requirements, } \mathrm{FEV}_{1} \text {, healthcare } \\
\text { utilisation }\end{array}$ \\
\hline Benralizumab & $\begin{array}{l}\text { Alpha } \\
\text { subunit of } \\
\text { IL-5 } \\
\text { receptor }\end{array}$ & $\begin{array}{l}\text { As an add on maintenance treatment } \\
\text { in adult patients with severe } \\
\text { eosinophilic asthma inadequately } \\
\text { controlled despite high-dose inhaled } \\
\text { corticosteroids plus long acting } \beta \\
\text { agonists. }\end{array}$ & $\begin{array}{l}30 \mathrm{mg} 4 \text { weekly for the first three } \\
\text { doses, then } 8 \text { weekly subcutaneously }\end{array}$ & $\begin{array}{l}\text { Improvement in } \\
\text { exacerbations, OCS } \\
\text { requirements, healthcare } \\
\text { utilisation, } F E V_{1}, \\
\mathrm{AQLQ}^{243-245,258}\end{array}$ \\
\hline Dupilumab & $\begin{array}{l}\text { Alpha } \\
\text { subunit of } \\
\text { IL-4 } \\
\text { receptor }\end{array}$ & $\begin{array}{l}\text { Add-on maintenance treatment for } \\
\text { severe asthma with type } 2 \\
\text { inflammation characterised by raised } \\
\text { blood eosinophils and/or raised } \\
\text { fraction of exhaled nitric oxide, who } \\
\text { are inadequately controlled with high } \\
\text { dose ICS plus another medicinal } \\
\text { product for maintenance treatment. }\end{array}$ & $\begin{array}{l}\text { If on OCS }+ \text { moderate-severe atopic } \\
\text { eczema/CRSwNP: loading dose of } \\
600 \mathrm{mg} \text { followed by } 300 \mathrm{mg} 2 \text { weekly } \\
400 \mathrm{mg} \text { loading dose followed by } \\
200 \mathrm{mg} 2 \text { weekly, subcutaneously }\end{array}$ & $\begin{array}{l}\text { Improvement in asthma } \\
\text { control, exacerbations, } \mathrm{FEV}_{1} \text {, } \\
\text { OCS requirements }\end{array}$ \\
\hline
\end{tabular}

Abbreviations: IgE, immunoglobulin E; FEV ${ }_{1}$, forced expiratory volume in I second; OCS, oral corticosteroid; AQLQ, asthma quality of life questionnaire; ICS, inhaled corticosteroids; IgE, Immunoglobulin E; IL-5, Interleukin-5; IL-4, Interleukin-4.

with activation of downstream T-cell mediated allergic inflammation. ${ }^{205}$ Indeed, high specific IgE levels are associated with increased asthma healthcare utilization ${ }^{206}$ and asthma severity. ${ }^{207}$ Omalizumab was the first monoclonal antibody licensed for use in severe allergic asthma. It binds free IgE, thus preventing IgE binding to FceRI on effector cells which are consequently down-regulated, ${ }^{208}$ and also inhibits $\mathrm{CD} 23,{ }^{208}$ a key player in antigen presentation. Over long term therapy, this drug also reduces $\operatorname{IgE}$ production, ${ }^{208}$ which may partly explain ongoing clinical efficacy with treatment cessation after long term use. ${ }^{209}$ Real-world studies have shown that the typical patients receiving Omalizumab are younger in age, have earlyonset asthma, and had a higher reported history of co- 
morbid atopic conditions such as allergic rhinitis. ${ }^{20,26}$ The multidimensional clinical efficacy of Omalizumab in such patients has been shown in meta-analyses of clinical trials. ${ }^{210}$ Similarly, in meta-analyses of real-world observational studies, Omalizumab response rates are around $77 \%,{ }^{211}$ with associated significantly improved exacerbation rate, $\mathrm{FEV}_{1}$, oral corticosteroid use, and health care utilisation. ${ }^{21,212}$ Besides this, Omalizumab's real-world long-term safety profile is also well-established, with prospective studies suggesting no increased risk of side effects, such as anaphylaxis or malignancy. ${ }^{213-215}$ Importantly, a recent and ongoing prospective study (EXPECT) has also provided valuable insights into Omalizumab's safety in pregnancy. The investigators showed that the prevalence of major congenital defects, pre-term birth and other pregnancy-related adverse outcomes were not raised in Omalizumab treated pregnant women, compared to the general asthma population. ${ }^{216}$ This may be useful to guide clinicians in biologic selection, in women planning pregnancy or who are pregnant, after careful consideration of risks and benefits, through joint decision making. Nonetheless, despite many years in clinical use, there is no agreement on factors predictive of Omalizumab treatment success. Post-hoc analyses of data from seven Omalizumab clinical trials found no baseline clinical characteristics reliably predicted Omalizumab efficacy. ${ }^{217}$ Baseline circulating $\operatorname{IgE}$ levels have also shown little utility in this regard. ${ }^{218} \mathrm{BEC}$, a surrogate marker of $\mathrm{T} 2$ status, displayed potential utility as a biomarker in post-hoc analyses of pivotal clinical trials, ${ }^{219}$ and in the EXTRA study. ${ }^{220}$ However, large prospective and retrospective real-world studies found that patients responded equally well to Omalizumab regardless of their baseline BEC. ${ }^{221-223}$ A similar discordance between real-world and clinical trial data regarding the utility of FeNO in response prediction was also observed. ${ }^{220,221,223}$ Serum periostin, a marker of persistent T2 inflammation ${ }^{61}$ has shown potential as a stable and replicable biomarker of Omalizumab efficacy in both clinical trial ${ }^{213}$ and realworld data. ${ }^{223}$ Indeed, post-hoc analysis of clinical trial data found that this biomarker had much lower intrapatient variability compared to measures such as FeNO. ${ }^{220}$ However, its utility may be limited by cost and it has yet to prove sufficiently compelling to cross over from an interesting research tool to mainstream clinical measure. Loss of efficacy or treatment failure inadvertently occurs in some Omalizumab treated patients. Interestingly, the severe eosinophilic and severe allergic phenotypes are known to overlap. ${ }^{224}$ Indeed, we have previously shown that around $40 \%$ of Omalizumab treated patients potentially qualify for Mepolizumab, had it been available at the time. ${ }^{26}$ Furthermore, there have been emerging real-world data on biologic switching from anti-IgE to anti-eosinophil agents ${ }^{22,226}$ in dual-eligible patients who did not respond to Omalizumab. This includes a real-world multicentre clinical trial $(\mathrm{OSMO})^{227}$ where switching has shown to not only be safe, but also efficacious in improving asthma control, healthcare utilization and exacerbations, even without an Omalizumab washout period. Thus, in the current multiple biologics era, patients who have lost efficacy on Omalizumab should be worked up to be potentially switched to another class of biologic, such as anti-eosinophil treatments, depending on their biomarkers and other treatable traits.

\section{Eosinophil-Targeting Biologics (Mepolizumab, Reslizumab and Benralizumab)}

IL-5 is a key mediator in eosinophilic inflammation in asthma through enabling eosinophil survival, differentiation, maturation, migration and proliferation. ${ }^{228}$ Raised IL-5 has been shown to correlate with asthma severity. ${ }^{229}$ Additionally, it has also been shown to be implicated in airway remodelling in both murine and human models. ${ }^{230}$ In recent years, there has been an influx of monoclonal antibody therapies targeting this cytokine, licensed for patients who exhibit eosinophilia alongside meeting nation-specific severity criteria commonly defined by oral corticosteroid dependency. Such biologics include Mepolizumab 231,232 and Reslizumab, ${ }^{233,234}$ which target circulating IL-5 itself, while Benralizumab targets the alpha subunit of the IL-5 receptor (IL-5R). ${ }^{235-237}$ These biologics are eosinophil depleting and have been not only efficacious but also safe in clinical trials, whereby the common side effects (headache, injection site reactions, back pain, pharyngitis) were mostly mild-moderate. ${ }^{231-237}$ Real-world studies have similarly shown that these drugs were safe and efficacious, with response rates around $70 \%$, and improvements in clinical asthma outcomes (exacerbations, OCS dependence, asthma control, quality of life, lung function), as early as 4-weeks into therapy. ${ }^{26,238-248}$ Their clinical efficacy was also observed in real-world patients who had failed Omalizumab therapy. ${ }^{225,226,249,250}$ Real-world characterisation of patients receiving anti-IL-5/IL-5R drugs has identified 
a group who are older in age, have adult-onset asthma, predominantly male and have a high prevalence of nasal polyposis. ${ }^{20,26}$ Nonetheless, not all patients respond well to these drugs, despite careful patient selection. Notably, most real-world studies of the different anti-IL5 agents have found that those with a more severe baseline disease, measured in terms such as Asthma control questionnaire-6, were less likely to respond and "super-respond" to these drugs. ${ }^{26,239,241}$ This is understandable as patients with more severe, difficult asthma likely have multiple treatable traits beyond eosinophilic inflammation driving their poor symptom control. ${ }^{26,251}$ In such circumstances, switching between biologics within the same pathway may be useful. Indeed, several retrospective reports have shown that the switch from Mepolizumab non-responders to Benralizumab resulted in improvements in exacerbations, OCS dose and asthma control. ${ }^{242,251}$ Similar trends were also demonstrated for switching Mepolizumab to Reslizumab in a small single-blinded placebo-controlled trial. ${ }^{252}$ Nonetheless, despite these emerging signals, the source of such observations have small sample sizes. Thus, more robust, prospective data is required to help inform inclass switching. Such data is also needed to inform the safety of these agents in the context of pregnancy, given that there are only a few case reports of such use across the three agents to date. ${ }^{253,254}$ Regarding biomarkers, post-hoc analyses of clinical trial data have suggested that baseline BEC may potentially be the most useful predictor of treatment response to these agents. ${ }^{56,255-257}$ This was also observed in real-world settings, ${ }^{239,258}$ but not consistently. ${ }^{26,238,259,260}$ A large, realworld Australian registry of Mepolizumab found that those with high BEC are more likely to respond. ${ }^{239}$ Similarly, Kavanagh et al found higher baseline BEC predicted "super-response" in their UK, Benralizumab treated patients. ${ }^{258}$ However, they also showed BEC was not useful in predicting Mepolizumab response. ${ }^{258}$ Two multi-centre studies from Italy ${ }^{238,246}$ and another real-world UK study ${ }^{26}$ similarly did not find BEC useful in predicting treatment response. This discrepancy may reflect different patient groups or the limited utility of cross-sectional eosinophil evaluation. ${ }^{22}$ It could also be that in a subset of patients, IL-5 may not be the main determinant of their eosinophilmediated disease. ${ }^{261}$ In these patients, perhaps targeting other T2 cytokines such as IL-4 and IL-13, which are often coexpressed with IL-5, may be preferable.

\section{Dupilumab}

Dupilumab is a humanized monoclonal antibody directed against the alpha subunit of the IL4 receptor, which antagonizes both IL-4 and IL-13. ${ }^{48,262,263}$ These mediators induce key features of $\mathrm{T} 2$ driven allergic asthma such as goblet cell metaplasia, IgE production and bronchial hyperresponsiveness. ${ }^{7}$ Blockade of such mechanisms translates to improved clinical outcomes, as evidenced by this drug's efficacy in clinical trials. ${ }^{48,261-263}$ Additionally, post-hoc analyses of the QUEST clinical trial data found it was efficacious even in those without allergic asthma. ${ }^{264}$ Given its relatively recent and to date selective worldwide approval, limited real-world data is available for this drug. One of these was a multi-centre retrospective analysis on $^{256}$ unselected, severe asthma patients in France. ${ }^{265}$ These patients were at a therapeutic dead-end and prescribed Dupilumab on a nominative Authorization for Temporary Use basis. The authors found that the efficacy of Dupilumab in this real-world cohort was comparable to clinical trials, whereby this drug improved asthma control, exacerbations and medication requirements. ${ }^{265}$ Other reports similarly provide evidence for the aforementioned multidimensional real-world efficacy of Dupilumab. ${ }^{266-268}$ Even more crucially, in a real-life setting, this drug was efficacious in those who had failed treatment with other asthma biologics. ${ }^{265,267,268}$ Indeed, in a recent retrospective study, patients who had an insufficient response to anti-IL-5/IL-5R or anti-IgE biologics, who were then switched to Dupilumab, showed improvements in asthma control, exacerbations and OCS requirements. ${ }^{269}$ This again suggests that inadequate response to a specific biologic should not be accepted as implying poor response to other biologics. No definitively useful predictors of treatment response were found in these studies, including baseline BEC. This corroborates but also contrasts findings from clinical trials. A pivotal phase $2 \mathrm{~b}$ trial, ${ }^{263}$ and the phase 3 trials QUEST $^{48}$ and VENTURE ${ }^{262}$ study evidenced Dupilumab efficacy, regardless of the levels of this biomarker. However, these studies found more robust improvements in those with high $\mathrm{BEC}^{48,262,263}$ and FeNO. ${ }^{48,262}$ Regardless, while the evidence of the efficacy of this drug in real-world settings is emerging, more data is required to identify biomarkers of treatment response to Dupilumab, to aid patient selection. Additionally, while this drug has shown a good safety profile in clinical trials, whereby adverse effects were again mild-moderate (viral upper respiratory tract infection, eosinophillia, sinusitis, injection site reactions) ${ }^{202}$ there are yet no real-world, asthma-specific data on the long-term safety and efficacy of this drug. Similarly, while there are case reports and case series of the use of this drug in treating atopic 
dermatitis during pregnancy, ${ }^{270-272}$ there are none for asthma. In these regards, the ongoing Global Dupilumab registry (RAPID) ${ }^{273}$ may help fill this need.

\section{Monoclonal Antibody Selection for Asthma and Comorbidities}

Monoclonal antibody therapies are finding increased use in comorbid T2 conditions encountered alongside asthma. Dupilumab is currently licensed by the EMA for the treatment of moderate to severe atopic dermatitis and severe chronic rhinosinusitis with nasal polyps (CRSwNP). ${ }^{202}$ It also has a specific license from the EMA, for patients with severe T2 asthma who have co-existent severe eczema or CRSwNP. ${ }^{202}$ Similarly, anti-IL-5 and IL-5R drugs, following successful clinical trials, are also currently under assessment for approval by multiple regulatory bodies for use in other eosinophilic conditions such as Eosinophilic Granulomatosis with Polyangiitis, ${ }^{248,274} \mathrm{CRSwNP}^{275-277}$ and Eosinophilic oesophagitis. ${ }^{278}$ Mepolizumab specifically has been approved by the Food and Drug Administration for Eosinophilic Granulomatosis with Polyangiitis ${ }^{278}$ Finally, Omalizumab is also licensed for use in treatment-resistant chronic spontaneous urticaria and CRSwNP. ${ }^{198}$ The emergence of biologic use in these other disease states may conceivably inform asthma biologic choice in the future as shown in Figure 2. It also once again highlights the importance of a holistic "wholeperson" approach to phenotyping, by looking beyond asthma and considering comorbid treatable traits in biologic selection.

\section{Future Treatments}

Currently, licenced biologic treatments target downstream pathways of T2-inflammation and reduce exacerbation rates in study populations by approximately only $50 \%$. Furthermore, there are limited treatment options for the seemingly few patients with T2-low severe asthma. With improved understanding of the immunopathogenesis of asthma, additional therapeutic targets within inflammatory pathways are being explored.

Recently published data show the effectiveness of Tezepelumab, a biologic that targets upstream T2-inflammation, in patients with severe, uncontrolled asthma. ${ }^{279}$ Tezepelumab blocks thymic stromal lymphopoietin (TSLP)- an epithelial-cell-derived alarmin central to the regulation of T2-immunity. TSLP acts on numerous immune cells inducing the production of T2-cytokines, ultimately resulting in airway eosinophilia, AHR and

\section{Omalizumab}

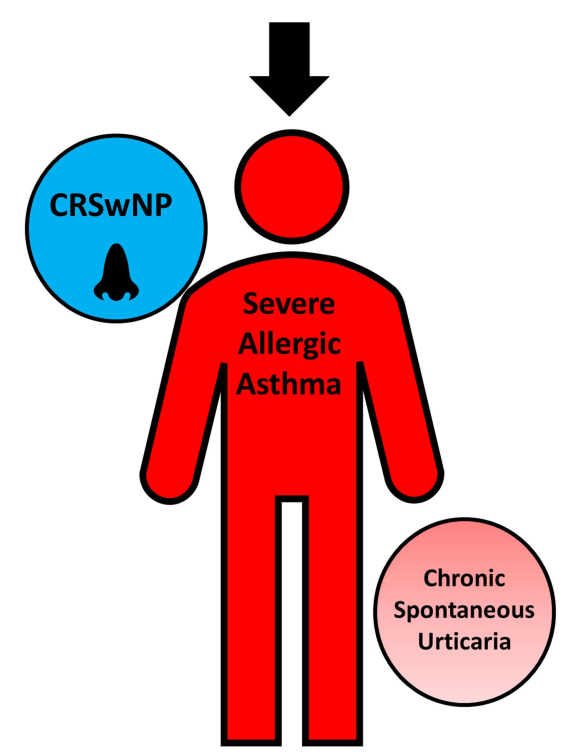

Mepolizumab Reslizumab Benralizumab

\section{Dupilumab}

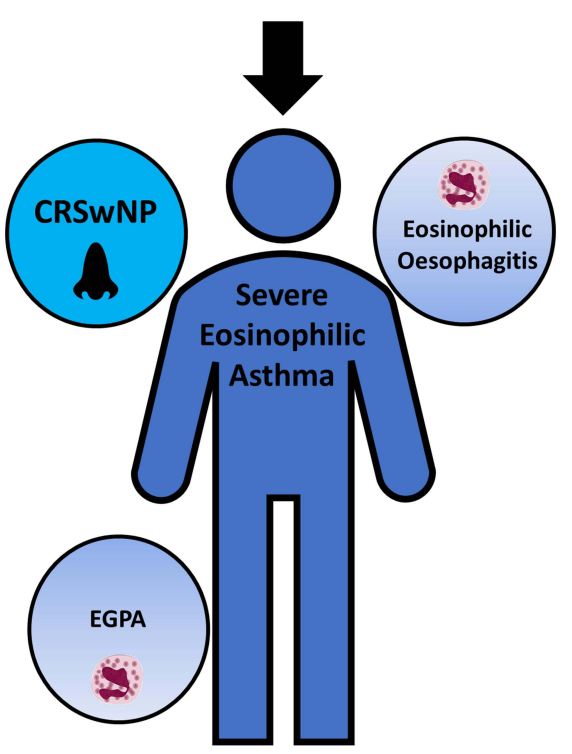

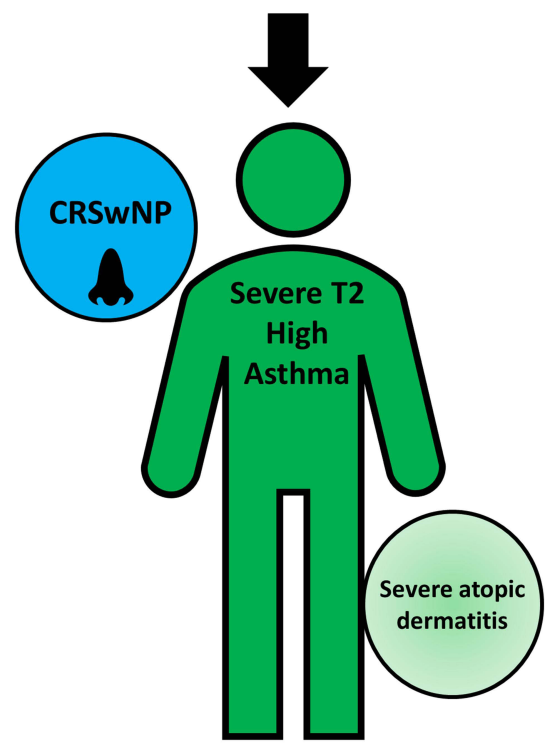

Figure 2 Biologic drugs in severe asthma and treatable traits potentially amenable to treatment by them. Abbreviations: CRSwNP, chronic rhinosinusitis with nasal polyps; EGPA, Eosinophilic Granulomatosis with Polyangiitis. 
airway remodelling. ${ }^{280-282}$ In NAVIGATOR, a phase 3 trial, patients who received Tezepelumab had significantly fewer exacerbations and better lung function, asthma control and health-related quality of life, regardless of BEC, although the benefits were greater in patients with $\mathrm{BEC} \geq$ 300 cells $/ \mu \mathrm{L}$.

Fevipiprant is an oral, highly selective, reversible antagonist of the prostaglandin D2 receptor (DP2). This receptor is expressed on key inflammatory cells including eosinophils, airway smooth much and epithelial cells. While Phase II studies in patients with asthma showed fevipiprant reduced sputum eosinophilia, improved lung function, as well as symptoms and quality of life, this efficacy was not replicated in a worldwide Phase 3 clinical trial programme. ${ }^{283}$ Nevertheless, there may be patient subgroups that benefit from fevipiprant and future studies are awaited.

Dexpramipexole is a novel oral eosinophil lowering drug which in a phase 2 study has been shown to significantly reduce $\mathrm{BEC}$ in patients with moderate-to-severe asthma. $^{284}$ The reduction in BEC was dose-dependent and seen alongside improvement in $\mathrm{FEV}_{1}$. It is thought to deplete eosinophils by inhibiting their maturation in the bone marrow, without affecting mature eosinophils. The drug is going to be studied as a potential pre-biologic alternative in the UK BEAT Severe Asthma Consortium Trials Program.

\section{Conclusion}

Asthma is a heterogeneous disease hallmarked by T2inflammatory pathways. Anti-inflammatory treatments are the mainstay of asthma treatment and ICS are now recommended for all patients with asthma. While conventional asthma treatments are broadly effective, recognising other treatable traits and using biomarkers to identify underlying inflammatory phenotypes helps to personalise treatment and improve asthma control. Monoclonal antibody treatments represent a new treatment era in severe asthma for patients who are uncontrolled despite high-dose antiinflammatory treatment. However, currently available biologics fail to prevent all exacerbations, highlighting once again the importance of treating other treatable traits and the need to continue to explore inflammatory pathways for novel therapeutic targets.

\section{Acknowledgments}

Joint corresponding authors: Wei Chern Gavin Fong and Ramesh J Kurukulaaratchy.

\section{Disclosure}

HR reports speaker and consultancy fees from AstraZeneca, GlaxoSmithKline, Teva, and Novartis and research grant funding from GlaxoSmithKline. WCGF reports ownership of AstraZeneca, GlaxoSmithKline And BioNTech shares. The aforementioned authors report no other potential conflicts of interest for this work. AK and RJK have no relevant conflicts of interest for this work to declare.

\section{References}

1. Global Initiative for Asthma. Global strategy for asthma management and prevention; 2021. Available from: www.ginasthma.org. Accessed August 17, 2021.

2. Rackemann FM. A working classification of asthma. Am J Med. 1947;3(5):601-606. doi:10.1016/0002-9343(47)90204-0

3. Brown HM. Treatment of chronic asthma with prednisolone; significance of eosinophils in the sputum. Lancet. 1958;272 (7059):1245-1247. doi:10.1016/S0140-6736(58)91385-0

4. Wenzel SE, Schwartz LB, Langmack EL, et al. Evidence that severe asthma can be divided pathologically into two inflammatory subtypes with distinct physiologic and clinical characteristics. Am J Respir Crit Care Med. 1999;160(3):1001-1008. doi:10.1164/ajrccm.160.3.9812110

5. Woodruff PG, Modrek B, Choy DF, et al. T-helper type 2-driven inflammation defines major subphenotypes of asthma. Am J Respir Crit Care Med. 2009;180(5):388-395. doi:10.1164/ rccm.200903-03920C

6. Lambrecht BN, Hammad H. The immunology of asthma. Nat Immunol. 2015;16(1):45-56. doi:10.1038/ni.3049

7. Lambrecht BN, Hammad H, Fahy JV. The cytokines of asthma. Immunity. 2019;50(4):975-991. doi:10.1016/j. immuni.2019.03.018

8. Ingram JL, Kraft M. IL-13 in asthma and allergic disease: asthma phenotypes and targeted therapies. J Allergy Clin Immunol. 2012;130(4):829-842; quiz 843-824. doi:10.1016/j. jaci.2012.06.034

9. Zhu Z, Homer RJ, Wang Z, et al. Pulmonary expression of interleukin-13 causes inflammation, mucus hypersecretion, subepithelial fibrosis, physiologic abnormalities, and eotaxin production. J Clin Invest. 1999;103(6):779-788. doi:10.1172/JCI5909

10. Pelaia C, Paoletti G, Puggioni F, et al. Interleukin-5 in the pathophysiology of severe asthma. Front Physiol. 2019;10:1514. doi:10.3389/fphys.2019.01514

11. Fitzpatrick AM, Chipps BE, Holguin F, Woodruff PG. T2-"low" asthma: overview and management strategies. J Allergy Clin Immunol Pract. 2020;8(2):452-463. doi:10.1016/j.jaip.20 19.11.006

12. Rakowski E, Zhao S, Liu M, et al. Variability of blood eosinophils in patients in a clinic for severe asthma. Clin Exp Allergy. 2019;49(2):163-170. doi:10.1111/cea.13310

13. Jatakanon A, Uasuf C, Maziak W, Lim S, Chung KF, Barnes PJ. Neutrophilic inflammation in severe persistent asthma. Am J Respir Crit Care Med. 1999;160(5):1532-1539. doi:10.1164/ ajrccm.160.5.9806170

14. Agache I, Ciobanu C, Agache C, Anghel M. Increased serum IL17 is an independent risk factor for severe asthma. Respir Med. 2010;104(8):1131-1137. doi:10.1016/j.rmed.2010.02.018

15. Al-Ramli W, Prefontaine D, Chouiali F, et al. T(H)17-associated cytokines (IL-17A and IL-17F) in severe asthma. J Allergy Clin Immunol. 2009;123(5):1185-1187. doi:10.1016/j.jaci.2009.02.024 
16. Tliba O, Panettieri RA. Paucigranulocytic asthma: uncoupling of airway obstruction from inflammation. J Allergy Clin Immunol. 2019;143(4):1287-1294. doi:10.1016/j.jaci.2018.06.008

17. Peters MC, McGrath KW, Hawkins GA, et al. Plasma interleukin6 concentrations, metabolic dysfunction, and asthma severity: a cross-sectional analysis of two cohorts. Lancet Respir Med. 2016;4(7):574-584. doi:10.1016/S2213-2600(16)30048-0

18. (GINA) GIFA. Difficult-to-treat and severe asthma in adolescent and adult patients: diagnosis and management. 2019.

19. (GINA) GIFA. Global strategy for asthma management and prevention. 2020

20. Jackson DJ, Busby J, Pfeffer PE, et al. Characterisation of patients with severe asthma in the UK severe asthma registry in the biologic era. Thorax. 2021;76(3):220-227. doi:10.1136/thoraxjnl-2020-215168

21. Heaney LG, Perez de Llano L, Al-Ahmad M, et al. Eosinophilic and noneosinophilic asthma: an expert consensus framework to characterize phenotypes in a global real-life severe asthma cohort. Chest. 2021:In Press. doi:10.1016/j.chest.2021.04.013

22. Azim A, Newell C, Barber C, et al. Clinical evaluation of type 2 disease status in a real-world population of difficult to manage asthma using historic electronic healthcare records of blood eosinophil counts. Clin Exp Allergy. 2021;51(6):811-820. doi:10.1111/cea.13841

23. Azim A, Freeman A, Lavenu A, et al. New perspectives on difficult asthma; sex and age of asthma-onset based phenotypes. J Allergy Clin Immunol Pract. 2020;8(10):3396-3406 e3394. doi:10.1016/j.jaip.2020.05.053

24. Lefaudeux D, De Meulder B, Loza MJ, et al. U-BIOPRED clinical adult asthma clusters linked to a subset of sputum omics. J Allergy Clin Immunol. 2017;139(6):1797-1807. doi:10.1016/j.jaci.2016.08.048

25. Moore WC, Meyers DA, Wenzel SE, et al. Identification of asthma phenotypes using cluster analysis in the severe asthma research program. Am J Respir Crit Care Med. 2010;181(4):315323. doi:10.1164/rccm.200906-0896OC

26. Fong WCG, Azim A, Knight D, et al. Real-world Omalizumab and Mepolizumab treated difficult asthma phenotypes and their clinical outcomes. Clin Exp Allergy. 2021;51:1019-1032. doi:10.1111/cea.13882

27. Molina C, Brun J, Coulet M, Betail G, Delage J. Immunopathology of the bronchial mucosa in 'late onset' asthma. Clin Allergy. 1977;7(2):137-145. doi:10.1111/j.1365-2222.1977. tb01434.x

28. Djukanovic R, Wilson JW, Britten KM, et al. Quantitation of mast cells and eosinophils in the bronchial mucosa of symptomatic atopic asthmatics and healthy control subjects using immunohistochemistry. Am Rev Respir Dis. 1990;142(4):863-871. doi:10.1164/ajrccm/142.4.863

29. Jarjour NN, Peters SP, Djukanovic R, Calhoun WJ. Investigative use of bronchoscopy in asthma. Am J Respir Crit Care Med. 1998;157(3):692-697. doi:10.1164/ajrccm.157.3.9705020

30. Simpson JL, Scott R, Boyle MJ, Gibson PG. Inflammatory subtypes in asthma: assessment and identification using induced sputum. Respirology. 2006;11(1):54-61. doi:10.1111/j.14401843.2006.00784.x

31. Louis R, Sele J, Henket M, et al. Sputum eosinophil count in a large population of patients with mild to moderate steroid-naive asthma: distribution and relationship with methacholine bronchial hyperresponsiveness. Allergy. 2002;57(10):907-912. doi:10.1034/ j.1398-9995.2002.23608.x

32. Green RH, Brightling CE, McKenna S, et al. Asthma exacerbations and sputum eosinophil counts: a randomised controlled trial. Lancet. 2002;360(9347):1715-1721. doi:10.1016/S0140-6736 (02)11679-5
33. Fleming L, Wilson N, Regamey N, Bush A. Use of sputum eosinophil counts to guide management in children with severe asthma. Thorax. 2012;67(3):193-198. doi:10.1136/ thx.2010.156836

34. Jones TB, Elliott T, Rupani S, et al. Characteristics of eosinophilic severe asthmatics in the Wessex Severe Asthma Cohort (WSAC). Eur Respir J. 2017;50:PA4042.

35. Ricciardolo FL. Revisiting the role of exhaled nitric oxide in asthma. Curr Opin Pulm Med. 2014;20(1):53-59. doi:10.1097/ MCP.0000000000000006

36. Chibana K, Trudeau JB, Mustovich AT, et al. IL-13 induced increases in nitrite levels are primarily driven by increases in inducible nitric oxide synthase as compared with effects on arginases in human primary bronchial epithelial cells. Clin Exp Allergy. 2008;38(6):936-946. doi:10.1111/j.1365-2222.20 08.02969.x

37. Ichinose $M$, Sugiura $H$, Yamagata $S$, Koarai A, Shirato K. Increase in reactive nitrogen species production in chronic obstructive pulmonary disease airways. Am J Respir Crit Care Med. 2000;162(2):701-706. doi:10.1164/ajrccm.162.2.9908132

38. Kupczyk M, Ten Brinke A, Sterk PJ, et al. Frequent exacerbatorsa distinct phenotype of severe asthma. Clin Exp Allergy. 2014;44 (2):212-221. doi:10.1111/cea.12179

39. Coumou H, Westerhof GA, de Nijs SB, Zwinderman AH, Bel EH. Predictors of accelerated decline in lung function in adultonset asthma. Eur Respir J. 2018;51(2):1701785. doi:10.1183/ 13993003.01785-2017

40. Matsunaga K, Hirano T, Oka A, Ito K, Edakuni N. Persistently high exhaled nitric oxide and loss of lung function in controlled asthma. Allergol Int. 2016;65(3):266-271. doi:10.1016/j. alit.2015.12.006

41. Vijverberg SJ, Hilvering B, Raaijmakers JA, Lammers JW, Maitland-van der Zee AH, Koenderman L. Clinical utility of asthma biomarkers: from bench to bedside. Biologics. 2013;7:199-210.

42. Dweik RA, Boggs PB, Erzurum SC, et al. An official ATS clinical practice guideline: interpretation of exhaled nitric oxide levels (FENO) for clinical applications. Am J Respir Crit Care Med. 2011;184(5):602-615. doi:10.1164/rccm.9120-11ST

43. Price DB, Buhl R, Chan A, et al. Fractional exhaled nitric oxide as a predictor of response to inhaled corticosteroids in patients with non-specific respiratory symptoms and insignificant bronchodilator reversibility: a randomised controlled trial. Lancet Respir Med. 2018;6(1):29-39. doi:10.1016/S2213-2600(17)30424-1

44. Cloutier MM, Baptist AP, Blake KV, et al. 2020 focused updates to the asthma management guidelines: a report from the National Asthma Education and Prevention Program Coordinating Committee Expert Panel Working Group. J Allergy Clin Immunol. 2020;146(6):1217-1270. doi:10.1016/j.jaci.20 20.10.003

45. McNicholl DM, Stevenson M, McGarvey LP, Heaney LG. The utility of fractional exhaled nitric oxide suppression in the identification of nonadherence in difficult asthma. Am J Respir Crit Care Med. 2012;186(11):1102-1108. doi:10.1164/rccm.20120405870C

46. Petsky HL, Cates CJ, Kew KM, Chang AB. Tailoring asthma treatment on eosinophilic markers (exhaled nitric oxide or sputum eosinophils): a systematic review and meta-analysis. Thorax. 2018;73(12):1110-1119. doi:10.1136/thoraxjnl-2018-211540

47. Korevaar DA, Westerhof GA, Wang J, et al. Diagnostic accuracy of minimally invasive markers for detection of airway eosinophilia in asthma: a systematic review and meta-analysis. Lancet Respir Med. 2015;3(4):290-300. doi:10.1016/S2213-2600(15) 00050-8 
48. Castro M, Corren J, Pavord ID, et al. Dupilumab efficacy and safety in moderate-to-severe uncontrolled asthma. $N$ Engl JMed. 2018;378:2486-2496. doi:10.1056/NEJMoa1804092

49. Pavord ID, Korn S, Howarth P, et al. Mepolizumab for severe eosinophilic asthma (DREAM): a multicentre, double-blind, placebo-controlled trial. Lancet. 2012;380(9842):651-659. doi:10.1016/S0140-6736(12)60988-X

50. Wagener AH, de Nijs SB, Lutter R, et al. External validation of blood eosinophils, $\mathrm{FE}(\mathrm{NO})$ and serum periostin as surrogates for sputum eosinophils in asthma. Thorax. 2015;70(2):115-120. doi:10.1136/thoraxjnl-2014-205634

51. Hancox RJ, Pavord ID, Sears MR. Associations between blood eosinophils and decline in lung function among adults with and without asthma. Eur Respir J. 2018;51(4):1702536. doi:10.1183/ 13993003.02536-2017

52. Tan WC, Bourbeau J, Nadeau G, et al. High eosinophil counts predict decline in $\mathrm{FEV}_{1}$ : results from the CanCOLD study. Eur Respir J. 2020;57:2000838.

53. Price D, Wilson AM, Chisholm A, et al. Predicting frequent asthma exacerbations using blood eosinophil count and other patient data routinely available in clinical practice. JAA. 2016;9:1-12.

54. Shrimanker R, Keene O, Hynes G, Wenzel S, Yancey S, Pavord ID. Prognostic and predictive value of blood eosinophil count, fractional exhaled nitric oxide, and their combination in severe asthma: a post hoc analysis. Am J Respir Crit Care Med. 2019;200(10):1308-1312. doi:10.1164/rccm.201903-0599LE

55. Price DB, Rigazio A, Campbell JD, et al. Blood eosinophil count and prospective annual asthma disease burden: a UK cohort study. Lancet Respir Med. 2015;3(11):849-858. doi:10.1016/S22132600(15)00367-7

56. Bleecker ER, Wechsler ME, FitzGerald JM, et al. Baseline patient factors impact on the clinical efficacy of benralizumab for severe asthma. Eur Respir J. 2018;52(4):1800936. doi:10.1183/ 13993003.00936-2018

57. Licari A, Manti S, Castagnoli R, Leonardi S, Marseglia GL. Measuring inflammation in paediatric severe asthma: biomarkers in clinical practice. Breathe. 2020;16(1):190301. doi:10.1183/ 20734735.0301-2019

58. Pavord ID, Afzalnia S, Menzies-Gow A, Heaney LG. The current and future role of biomarkers in type 2 cytokine-mediated asthma management. Clin Exp Allergy. 2017;47(2):148-160. doi:10.1111/ cea. 12881

59. Takayama G, Arima K, Kanaji T, et al. Periostin: a novel component of subepithelial fibrosis of bronchial asthma downstream of IL-4 and IL-13 signals. J Allergy Clin Immunol. 2006;118(1):98104. doi:10.1016/j.jaci.2006.02.046

60. Woodruff PG, Boushey HA, Dolganov GM, et al. Genome-wide profiling identifies epithelial cell genes associated with asthma and with treatment response to corticosteroids. Proc Natl Acad Sci USA. 2007;104(40):15858-15863. doi:10.1073/ pnas.0707413104

61. Jia G, Erickson RW, Choy DF, et al. Periostin is a systemic biomarker of eosinophilic airway inflammation in asthmatic patients. J Allergy Clin Immunol. 2012;130(3):647-654.e610. doi:10.1016/j.jaci.2012.06.025

62. Couillard S, Laugerud A, Jabeen M, et al. A proof-of-concept scale to predict asthma attacks: the OxfoRd Asthma attaCk risk ScaLE (ORACLE). Am J Respir Crit Care Med. 2021;203: A1436.

63. Parikh NI, Vasan RS. Assessing the clinical utility of biomarkers in medicine. Biomark Med. 2007;1(3):419-436. doi:10.2217/ 17520363.1.3.419

64. Gebert LFR, MacRae IJ. Regulation of microRNA function in animals. Nat Rev Mol Cell Biol. 2019;20(1):21-37.
65. Specjalski K, Niedoszytko M. MicroRNAs: future biomarkers and targets of therapy in asthma? Curr Opin Pulm Med. 2020;26(3):285-292. doi:10.1097/MCP.0000000000000673

66. Huang Y, Zhang S, Fang X, et al. Plasma miR-199a-5p is increased in neutrophilic phenotype asthma patients and negatively correlated with pulmonary function. PLoS One. 2018;13 (3):e0193502. doi:10.1371/journal.pone.0193502

67. Tian M, Zhou Y, Jia H, Zhu X, Cui Y. The clinical significance of changes in the expression levels of MicroRNA-1 and inflammatory factors in the peripheral blood of children with acute-stage asthma. Biomed Res Int. 2018;2018:7632487. doi:10.1155/2018/ 7632487

68. Maes T, Cobos FA, Schleich F, et al. Asthma inflammatory phenotypes show differential microRNA expression in sputum. $J$ Allergy Clin Immunol. 2016;137(5):1433-1446. doi:10.1016/j. jaci.2016.02.018

69. Zhao M, Juanjuan L, Weijia F, et al. Expression levels of microRNA-125b in serum exosomes of patients with asthma of different severity and its diagnostic significance. Curr Drug Metab. 2019;20(10):781-784. doi:10.2174/13892002206661 91021100001

70. Rodrigo-Munoz JM, Canas JA, Sastre B, et al. Asthma diagnosis using integrated analysis of eosinophil microRNAs. Allergy. 2019;74(3):507-517. doi:10.1111/all.13570

71. de Vries R, Dagelet YWF, Spoor P, et al. Clinical and inflammatory phenotyping by breathomics in chronic airway diseases irrespective of the diagnostic label. Eur Respir J. 2018;51 (1):1701817. doi:10.1183/13993003.01817-2017

72. Schleich FN, Zanella D, Stefanuto PH, et al. Exhaled volatile organic compounds are able to discriminate between neutrophilic and eosinophilic asthma. Am J Respir Crit Care Med. 2019;200 (4):444-453. doi:10.1164/rccm.201811-22100C

73. Brinkman P, van de Pol MA, Gerritsen MG, et al. Exhaled breath profiles in the monitoring of loss of control and clinical recovery in asthma. Clin Exp Allergy. 2017;47(9):1159-1169. doi:10.1111/ cea. 12965

74. Peel AM, Wilkinson M, Sinha A, Loke YK, Fowler SJ, Wilson AM. Volatile organic compounds associated with diagnosis and disease characteristics in asthma - a systematic review. Respir Med. 2020;169:105984. doi:10.1016/j.rmed.2020.105984

75. Holz O, Waschki B, Watz $\mathrm{H}$, et al. Breath volatile organic compounds and inflammatory markers in adult asthma patients: negative results from the ALLIANCE cohort. Eur Respir J. 2021;57 (2):2002127. doi:10.1183/13993003.02127-2020

76. Kolmert J, Gomez C, Balgoma D, et al. Urinary leukotriene E4 and prostaglandin D2 metabolites increase in adult and childhood severe asthma characterized by type 2 inflammation. A clinical observational study. Am J Respir Crit Care Med. 2021;203(1):3753. doi:10.1164/rccm.201909-1869OC

77. Hagan JB, Laidlaw TM, Divekar R, et al. Urinary leukotriene E4 to determine aspirin intolerance in asthma: a systematic review and meta-analysis. J Allergy Clin Immunol Pract. 2017;5(4):990997 e991. doi:10.1016/j.jaip.2016.11.004

78. Ostling J, van Geest M, Schofield JPR, et al. IL-17-high asthma with features of a psoriasis immunophenotype. J Allergy Clin Immunol. 2019;144(5):1198-1213. doi:10.1016/j. jaci.2019.03.027

79. Cowan DC, Taylor DR, Peterson LE, et al. Biomarker-based asthma phenotypes of corticosteroid response. J Allergy Clin Immunol. 2015;135(4):877-883 e871. doi:10.1016/j. jaci.2014.10.026

80. Denton E, Price DB, Tran TN, et al. Cluster analysis of inflammatory biomarker expression in the international severe asthma registry. J Allergy Clin Immunol Pract. 2021;9:2680-2688.e7. doi:10.1016/j.jaip.2021.02.059 
81. Fitzpatrick AM, Teague WG, Meyers DA, et al. Heterogeneity of severe asthma in childhood: confirmation by cluster analysis of children in the National Institutes of Health/National Heart, Lung, and Blood Institute Severe Asthma Research Program. J Allergy Clin Immunol. 2011;127(2):382-389. doi:10.1016/j.jaci.2010.11.015

82. Kurukulaaratchy RJ, Zhang H, Raza A, et al. The diversity of young adult wheeze: a cluster analysis in a longitudinal birth cohort. Clin Exp Allergy. 2014;44(5):724-735. doi:10.1111/cea.12306

83. Pavord ID, Beasley R, Agusti A, et al. After asthma: redefining airways diseases. Lancet. 2018;391(10118):350-400.

84. Agusti A, Bel E, Thomas M, et al. Treatable traits: toward precision medicine of chronic airway diseases. Eur Respir J. 2016;47 (2):410-419. doi:10.1183/13993003.01359-2015

85. Freitas PD, Xavier RF, McDonald VM, et al. Identification of asthma phenotypes based on extrapulmonary treatable traits. Eur Respir J. 2021;57(1):2000240. doi:10.1183/13993003.002402020

86. McDonald VM, Hiles SA, Godbout K, et al. Treatable traits can be identified in a severe asthma registry and predict future exacerbations. Respirology. 2019;24(1):37-47. doi:10.1111/resp.13389

87. Simpson AJ, Hekking PP, Shaw DE, et al. Treatable traits in the European U-BIOPRED adult asthma cohorts. Allergy. 2019;74 (2):406-411. doi:10.1111/all.13629

88. Tay TR, Radhakrishna N, Hore-Lacy F, et al. Comorbidities in difficult asthma are independent risk factors for frequent exacerbations, poor control and diminished quality of life. Respirology. 2016;21(8):1384-1390. doi:10.1111/resp.12838

89. McDonald VM, Clark VL, Cordova-Rivera L, Wark PAB, Baines KJ, Gibson PG. Targeting treatable traits in severe asthma: a randomised controlled trial. Eur Respir J. 2020;55(3):1901509. doi:10.1183/13993003.01509-2019

90. Flood-Page PT, Menzies-Gow AN, Kay AB, Robinson DS. Eosinophil's role remains uncertain as anti-interleukin-5 only partially depletes numbers in asthmatic airway. Am J Respir Crit Care Med. 2003;167(2):199-204. doi:10.1164/rccm.200208$7890 \mathrm{C}$

91. Haldar P, Brightling CE, Hargadon B, et al. Mepolizumab and exacerbations of refractory eosinophilic asthma. $N$ Engl J Med. 2009;360(10):973-984. doi:10.1056/NEJMoa0808991

92. Nair P, Pizzichini MM, Kjarsgaard M, et al. Mepolizumab for prednisone-dependent asthma with sputum eosinophilia. $N$ Engl J Med. 2009;360(10):985-993. doi:10.1056/NEJMoa0805435

93. Green RH, Brightling CE, Woltmann G, Parker D, Wardlaw AJ, Pavord ID. Analysis of induced sputum in adults with asthma: identification of subgroup with isolated sputum neutrophilia and poor response to inhaled corticosteroids. Thorax. 2002;57 (10):875-879. doi:10.1136/thorax.57.10.875

94. Moore WC, Hastie AT, Li X, et al. Sputum neutrophil counts are associated with more severe asthma phenotypes using cluster analysis. $J$ Allergy Clin Immunol. 2014;133(6):1557-1563 e1555. doi:10.1016/j.jaci.2013.10.011

95. Shaw DE, Berry MA, Hargadon B, et al. Association between neutrophilic airway inflammation and airflow limitation in adults with asthma. Chest. 2007;132(6):1871-1875. doi:10.1378/ chest.07-1047

96. Boulet LP, Lemiere C, Archambault F, Carrier G, Descary MC, Deschesnes F. Smoking and asthma: clinical and radiologic features, lung function, and airway inflammation. Chest. 2006;129 (3):661-668. doi:10.1378/chest.129.3.661

97. Green BJ, Wiriyachaiporn S, Grainge C, et al. Potentially pathogenic airway bacteria and neutrophilic inflammation in treatment resistant severe asthma. PLoS One. 2014;9(6):e100645. doi:10.1371/journal.pone.0100645

98. McCreanor J, Cullinan P, Nieuwenhuijsen MJ, et al. Respiratory effects of exposure to diesel traffic in persons with asthma. $N$ Engl J Med. 2007;357(23):2348-2358. doi:10.1056/NEJMoa071535
99. Hastie AT, Mauger DT, Denlinger LC, et al. Mixed sputum granulocyte longitudinal impact on lung function in the severe asthma research program. Am J Respir Crit Care Med. 2021;203 (7):882-892. doi:10.1164/rccm.202009-3713OC

100. Hastie AT, Moore WC, Meyers DA, et al. Analyses of asthma severity phenotypes and inflammatory proteins in subjects stratified by sputum granulocytes. J Allergy Clin Immunol. 2010;125 (5):1028-1036 e1013. doi:10.1016/j.jaci.2010.02.008

101. Ntontsi P, Loukides S, Bakakos P, et al. Clinical, functional and inflammatory characteristics in patients with paucigranulocytic stable asthma: comparison with different sputum phenotypes. Allergy. 2017;72(11):1761-1767. doi:10.1111/all.13184

102. Svenningsen S, Nair P. Asthma endotypes and an overview of targeted therapy for asthma. Front Med (Lausanne). 2017;4:158. doi:10.3389/fmed.2017.00158

103. Shin B, Kwon HS, Park SY, Kim TB, Moon HB, Cho YS. The transition of sputum inflammatory cell profiles is variable in stable asthma patients. Asia Pac Allergy. 2017;7(1):19-28. doi:10.5415/apallergy.2017.7.1.19

104. Denning DW, O'Driscoll BR, Hogaboam CM, Bowyer P, Niven RM. The link between fungi and severe asthma: a summary of the evidence. Eur Respir J. 2006;27(3):615-626. doi:10.1183/ 09031936.06 .00074705

105. Rick EM, Woolnough K, Pashley CH, Wardlaw AJ. Allergic fungal airway disease. $J$ Investig Allergol Clin Immunol. 2016;26(6):344-354. doi:10.18176/jiaci.0122

106. Fairs A, Agbetile J, Hargadon B, et al. IgE sensitization to Aspergillus fumigatus is associated with reduced lung function in asthma. Am J Respir Crit Care Med. 2010;182(11):1362-1368. doi:10.1164/rccm.201001-0087OC

107. Goh KJ, Yii ACA, Lapperre TS, et al. Sensitization to Aspergillus species is associated with frequent exacerbations in severe asthma. J Asthma Allergy. 2017;10:131-140. doi:10.2147/JAA. S130459

108. Medrek SK, Kao CC, Yang DH, Hanania NA, Parulekar AD. Fungal sensitization is associated with increased risk of lifethreatening asthma. J Allergy Clin Immunol Pract. 2017;5 (4):1025-1031 e1022. doi:10.1016/j.jaip.2016.11.015

109. Menzies D, Holmes L, McCumesky G, Prys-Picard C, Niven R. Aspergillus sensitization is associated with airflow limitation and bronchiectasis in severe asthma. Allergy. 2011;66(5):679-685. doi:10.1111/j.1398-9995.2010.02542.x

110. O’Driscoll BR, Hopkinson LC, Denning DW. Mold sensitization is common amongst patients with severe asthma requiring multiple hospital admissions. BMC Pulm Med. 2005;5:4. doi:10.1186/ 1471-2466-5-4

111. Targonski PV, Persky VW, Ramekrishnan V. Effect of environmental molds on risk of death from asthma during the pollen season. J Allergy Clin Immunol. 1995;95(5):955-961. doi:10.1016/S0091-6749(95)70095-1

112. Woolnough KF, Richardson M, Newby C, et al. The relationship between biomarkers of fungal allergy and lung damage in asthma. Clin Exp Allergy. 2017;47(1):48-56. doi:10.1111/ cea. 12848

113. Wark PA, Saltos N, Simpson J, Slater S, Hensley MJ, Gibson PG. Induced sputum eosinophils and neutrophils and bronchiectasis severity in allergic bronchopulmonary aspergillosis. Eur Respir J. 2000;16(6):1095-1101. doi:10.1034/j.1399-3003.2000.16f13.x

114. Denning DW, Pashley C, Hartl D, et al. Fungal allergy in asthmastate of the art and research needs. Clin Transl Allergy. 2014;4:14. doi:10.1186/2045-7022-4-14

115. Li JX, Fan LC, Li MH, Cao WJ, Xu JF. Beneficial effects of Omalizumab therapy in allergic bronchopulmonary aspergillosis: a synthesis review of published literature. Respir Med. 2017;122:33-42. doi:10.1016/j.rmed.2016.11.019 
116. Wark PA, Gibson PG, Wilson AJ. Azoles for allergic bronchopulmonary aspergillosis associated with asthma. Cochrane Database Syst Rev. 2004;2004(3):CD001108. doi:10.1002/ 14651858.CD001108.pub2

117. Szczeklik A, Nizankowska E, Duplaga M. Natural history of aspirin-induced asthma. AIANE investigators. European network on aspirin-induced asthma. Eur Respir J. 2000;16(3):432-436. doi:10.1034/j.1399-3003.2000.016003432.x

118. Christie PE, Tagari P, Ford-Hutchinson AW, et al. Urinary leukotriene E4 concentrations increase after aspirin challenge in aspirin-sensitive asthmatic subjects. Am Rev Respir Dis. 1991;143(5 Pt 1):1025-1029. doi:10.1164/ajrccm/ 143.5_Pt 1.1025

119. White AA, Stevenson DD, Longo DL. Aspirin-exacerbated respiratory disease. $N$ Engl J Med. 2018;379(11):1060-1070. doi:10.1056/NEJMra1712125

120. Adelman J, McLean C, Shaigany K, Krouse JH. The role of surgery in management of Samter's triad: a systematic review. Otolaryngol Head Neck Surg. 2016;155(2):220-237. doi:10.1177/ 0194599816640723

121. Sommer DD, Rotenberg BW, Sowerby LJ, et al. A novel treatment adjunct for aspirin exacerbated respiratory disease: the lowsalicylate diet: a multicenter randomized control crossover trial. Int Forum Allergy Rhinol. 2016;6(4):385-391. doi:10.1002/ alr.21678

122. Waldram J, Walters K, Simon R, Woessner K, Waalen J, White A. Safety and outcomes of aspirin desensitization for aspirin-exacerbated respiratory disease: a single-center study. J Allergy Clin Immunol. 2018;141(1):250-256. doi:10.1016/j.jaci.2017.05.006

123. Hayashi H, Mitsui C, Nakatani E, et al. Omalizumab reduces cysteinyl leukotriene and 9alpha, 11beta-prostaglandin F2 overproduction in aspirin-exacerbated respiratory disease. J Allergy Clin Immunol. 2016;137(5):1585-1587 e1584. doi:10.1016/j. jaci.2015.09.034

124. Bousquet J, Vignola AM, Demoly P. Links between rhinitis and asthma. Allergy. 2003;58(8):691-706. doi:10.1034/j.13989995.2003.00105.x

125. de Groot EP, Nijkamp A, Duiverman EJ, Brand PL. Allergic rhinitis is associated with poor asthma control in children with asthma. Thorax. 2012;67(7):582-587. doi:10.1136/thoraxjnl2011-201168

126. Kurukulaaratchy RJ, Zhang H, Patil V, et al. Identifying the heterogeneity of young adult rhinitis through cluster analysis in the Isle of Wight birth cohort. J Allergy Clin Immunol. 2015;135 (1):143-150. doi:10.1016/j.jaci.2014.06.017

127. Scichilone N, Arrigo R, Paterno A, et al. The effect of intranasal corticosteroids on asthma control and quality of life in allergic rhinitis with mild asthma. $J$ Asthma. 2011;48(1):41-47. doi:10.3109/02770903.2010.528821

128. Scadding GK, Kariyawasam HH, Scadding G, et al. BSACI guideline for the diagnosis and management of allergic and nonallergic rhinitis (Revised Edition 2017; First edition 2007). Clin Exp Allergy. 2017;47(7):856-889.

129. Bilodeau L, Boulay ME, Prince P, Boisvert P, Boulet LP. Comparative clinical and airway inflammatory features of asthmatics with or without polyps. Rhinology. 2010;48(4):420-425. doi:10.4193/Rhino09.095

130. Hakansson K, Bachert C, Konge L, et al. Airway inflammation in chronic rhinosinusitis with nasal polyps and asthma: the united airways concept further supported. PLoS One. 2015;10(7): e0127228. doi:10.1371/journal.pone.0127228

131. Jarvis D, Newson R, Lotvall J, et al. Asthma in adults and its association with chronic rhinosinusitis: the GA2LEN survey in Europe. Allergy. 2012;67(1):91-98. doi:10.1111/j.13989995.2011.02709.x
132. Bachert C, Zhang N, Patou J, van Zele T, Gevaert P. Role of staphylococcal superantigens in upper airway disease. Curr Opin Allergy Clin Immunol. 2008;8(1):34-38. doi:10.1097/ ACI.0b013e3282f4178f

133. Fokkens WJ, Lund VJ, Hopkins C, et al. Executive summary of EPOS 2020 including integrated care pathways. Rhinology. 2020;58(2):82-111. doi:10.4193/Rhin20.601

134. Al Badaai Y, Valdes CJ, Samaha M. Outcomes and cost benefits of functional endoscopic sinus surgery in severely asthmatic patients with chronic rhinosinusitis. $J$ Laryngol Otol. 2014;128 (6):512-517. doi:10.1017/S0022215114001133

135. Chen FH, Zuo KJ, Guo YB, et al. Long-term results of endoscopic sinus surgery-oriented treatment for chronic rhinosinusitis with asthma. Laryngoscope. 2014;124(1):24-28. doi:10.1002/ lary. 24196

136. Ragab S, Scadding GK, Lund VJ, Saleh H. Treatment of chronic rhinosinusitis and its effects on asthma. Eur Respir J. 2006;28 (1):68-74. doi:10.1183/09031936.06.00043305

137. Holguin F, Bleecker ER, Busse WW, et al. Obesity and asthma: an association modified by age of asthma onset. J Allergy Clin Immunol. 2011;127(6):1486-1493 e1482. doi:10.1016/j. jaci.2011.03.036

138. Dixon AE, Peters U. The effect of obesity on lung function. Expert Rev Respir Med. 2018;12(9):755-767. doi:10.1080/ 17476348.2018.1506331

139. Brumpton BM, Camargo CA, Romundstad PR, Langhammer A, Chen Y, Mai XM. Metabolic syndrome and incidence of asthma in adults: the HUNT study. Eur Respir J. 2013;42(6):1495-1502. doi: $10.1183 / 09031936.00046013$

140. Forno E, Han YY, Muzumdar RH, Celedon JC. Insulin resistance, metabolic syndrome, and lung function in US adolescents with and without asthma. $J$ Allergy Clin Immunol. 2015;136(2):304311 e308. doi:10.1016/j.jaci.2015.01.010

141. Kattan M, Kumar R, Bloomberg GR, et al. Asthma control, adiposity, and adipokines among inner-city adolescents. $J$ Allergy Clin Immunol. 2010;125(3):584-592. doi:10.1016/j. jaci.2010.01.053

142. Scott HA, Gibson PG, Garg ML, Wood LG. Airway inflammation is augmented by obesity and fatty acids in asthma. Eur Respir J. 2011;38(3):594-602. doi:10.1183/09031936.001 39810

143. Hasegawa K, Tsugawa Y, Chang Y, Camargo CA. Risk of an asthma exacerbation after bariatric surgery in adults. J Allergy Clin Immunol. 2015;136(2):288-294 e288. doi:10.1016/j.jaci.2014.12.1931

144. Nyenhuis SM, Dixon AE, Ma J. Impact of lifestyle interventions targeting healthy diet, physical activity, and weight loss on asthma in adults: what is the evidence? $J$ Allergy Clin Immunol Pract. 2018;6(3):751-763. doi:10.1016/j.jaip.2017.10.026

145. Okoniewski W, Lu KD, Forno E. Weight loss for children and adults with obesity and asthma. A systematic review of randomized controlled trials. Ann Am Thorac Soc. 2019;16(5):613-625. doi:10.1513/AnnalsATS.201810-651SR

146. van Huisstede A, Rudolphus A, Castro Cabezas M, et al. Effect of bariatric surgery on asthma control, lung function and bronchial and systemic inflammation in morbidly obese subjects with asthma. Thorax. 2015;70(7):659-667. doi:10.1136/thoraxjnl2014-206712

147. Chalmers GW, Macleod KJ, Little SA, Thomson LJ, McSharry $\mathrm{CP}$, Thomson NC. Influence of cigarette smoking on inhaled corticosteroid treatment in mild asthma. Thorax. 2002;57 (3):226-230. doi:10.1136/thorax.57.3.226

148. Lazarus SC, Chinchilli VM, Rollings NJ, et al. Smoking affects response to inhaled corticosteroids or leukotriene receptor antagonists in asthma. Am J Respir Crit Care Med. 2007;175(8):783790. doi:10.1164/rccm.200511-1746OC 
149. Chaudhuri R, Livingston E, McMahon AD, et al. Effects of smoking cessation on lung function and airway inflammation in smokers with asthma. Am J Respir Crit Care Med. 2006;174 (2):127-133. doi:10.1164/rccm.200510-1589OC

150. Perret JL, Bonevski B, McDonald CF, Abramson MJ. Smoking cessation strategies for patients with asthma: improving patient outcomes. J Asthma Allergy. 2016;9:117-128. doi:10.2147/JAA. S85615

151. Gamble J, Stevenson M, McClean E, Heaney LG. The prevalence of nonadherence in difficult asthma. Am J Respir Crit Care Med. 2009;180(9):817-822. doi:10.1164/rccm.200902-0166OC

152. Murphy AC, Proeschal A, Brightling CE, et al. The relationship between clinical outcomes and medication adherence in difficultto-control asthma. Thorax. 2012;67(8):751-753. doi:10.1136/ thoraxjnl-2011-201096

153. Alahmadi F, Peel A, Keevil B, Niven R, Fowler SJ. Assessment of adherence to corticosteroids in asthma by drug monitoring or fractional exhaled nitric oxide: a literature review. Clin Exp Allergy. 2021;51(1):49-62. doi:10.1111/cea.13787

154. Averell CM, Stanford RH, Laliberte F, Wu JW, Germain G, Duh MS. Medication adherence in patients with asthma using oncedaily versus twice-daily ICS/LABAs. J Asthma. 2021;58(1):102111. doi:10.1080/02770903.2019.1663429

155. Heaney LG, Busby J, Bradding P, et al. Remotely monitored therapy and nitric oxide suppression identifies nonadherence in severe asthma. Am J Respir Crit Care Med. 2019;199(4):454464. doi:10.1164/rccm.201806-1182OC

156. Moore A, Preece A, Sharma R, et al. A randomised controlled trial of the effect of a connected inhaler system on medication adherence in uncontrolled asthmatic patients. Eur Respir J. 2021;57(6):2003103. doi:10.1183/13993003.03103-2020

157. Mosnaim G, Safioti G, Brown R, et al. Digital health technology in asthma: a comprehensive scoping review. J Allergy Clin Immunol Pract. 2021;9:2377-2398. doi:10.1016/j. jaip.2021.02.028

158. Wells KE, Peterson EL, Ahmedani BK, Williams LK. Real-world effects of once vs greater daily inhaled corticosteroid dosing on medication adherence. Ann Allergy Asthma Immunol. 2013;111 (3):216-220. doi:10.1016/j.anai.2013.06.008

159. Papi A, Blasi F, Canonica GW, Morandi L, Richeldi L, Rossi A. Treatment strategies for asthma: reshaping the concept of asthma management. Allergy Asthma Clin Immunol. 2020;16:75. doi:10.1186/s13223-020-00472-8

160. Dusser D, Montani D, Chanez P, et al. Mild asthma: an expert review on epidemiology, clinical characteristics and treatment recommendations. Allergy. 2007;62(6):591-604. doi:10.1111/ j.1398-9995.2007.01394.x

161. Miller MK, Lee JH, Miller DP, Wenzel SE, Group TS. Recent asthma exacerbations: a key predictor of future exacerbations. Respir Med. 2007;101(3):481-489. doi:10.1016/j. rmed.2006.07.005

162. Suissa S, Ernst P, Benayoun S, Baltzan M, Cai B. Low-dose inhaled corticosteroids and the prevention of death from asthma. $N$ Engl J Med. 2000;343(5):332-336. doi:10.1056/ NEJM200008033430504

163. Suissa S, Ernst P, Kezouh A. Regular use of inhaled corticosteroids and the long term prevention of hospitalisation for asthma Thorax. 2002;57(10):880-884. doi:10.1136/thorax.57.10.880

164. Haahtela T, Tuomisto LE, Pietinalho A, et al. A 10 year asthma programme in Finland: major change for the better. Thorax 2006;61(8):663. doi:10.1136/thx.2005.055699

165. Barnes CB, Ulrik CS. Asthma and adherence to inhaled corticosteroids: current status and future perspectives. Respir Care. 2015;60(3):455-468. doi:10.4187/respcare.03200

166. Bateman ED, Reddel HK, FitzGerald JM. As-needed budesonideformoterol in mild asthma. N Engl J Med. 2018;379(9):898.
167. Beasley R, Weatherall M, Shirtcliffe P, Hancox R, Reddel HK. Combination corticosteroid/beta-agonist inhaler as reliever therapy: a solution for intermittent and mild asthma? J Allergy Clin Immunol. 2014;133(1):39-41. doi:10.1016/j.jaci.2013.10.053

168. Price D, Fletcher M, van der Molen T. Asthma control and management in 8000 European patients: the REcognise Asthma and LInk to Symptoms and Experience (REALISE) survey. NPJ Prim Care Respir Med. 2014;24:14009. doi:10.1038/ npjpcrm.2014.9

169. O’Byrne PM, FitzGerald JM, Bateman ED, et al. Inhaled combined budesonide-formoterol as needed in mild asthma. $N$ Engl $J$ Med. 2018;378(20):1865-1876. doi:10.1056/NEJMoa1715274

170. Beasley R, Holliday M, Reddel HK, et al. Controlled trial of budesonide-formoterol as needed for mild asthma. $N$ Engl JMed. 2019;380(21):2020-2030. doi:10.1056/NEJMoa1901963

171. Sobieraj DM, Weeda ER, Nguyen E, et al. Association of inhaled corticosteroids and long-acting $\beta$-agonists as controller and quick relief therapy with exacerbations and symptom control in persistent asthma: a systematic review and meta-analysis. JAMA. 2018;319(14):1485-1496. doi:10.1001/jama.2018.2769

172. Tattersfield AE, Postma DS, Barnes PJ, et al. Exacerbations of asthma: a descriptive study of 425 severe exacerbations. The FACET International Study Group. Am J Respir Crit Care Med. 1999;160(2):594-599. doi:10.1164/ajrccm.160.2.9811100

173. Rabe KF, Atienza T, Magyar P, Larsson P, Jorup C, Lalloo UG. Effect of budesonide in combination with formoterol for reliever therapy in asthma exacerbations: a randomised controlled, double-blind study. Lancet. 2006;368(9537):744-753. doi:10.1016/ S0140-6736(06)69284-2

174. Kuna P, Peters MJ, Manjra AI, et al. Effect of budesonide/formoterol maintenance and reliever therapy on asthma exacerbations. Int J Clin Pract. 2007;61(5):725-736. doi:10.1111/j.17421241.2007.01338.x

175. Bousquet J, Boulet LP, Peters MJ, et al. Budesonide/formoterol for maintenance and relief in uncontrolled asthma vs. high-dose salmeterol/fluticasone. Respir Med. 2007;101(12):2437-2446. doi:10.1016/j.rmed.2007.07.014

176. Lazarus SC, Krishnan JA, King TS, et al. Mometasone or tiotropium in mild asthma with a low sputum eosinophil level. $N$ Engl JMed. 2019;380(21):2009-2019. doi:10.1056/NEJMoa1814917

177. Leach C, Colice GL, Luskin A. Particle size of inhaled corticosteroids: does it matter? J Allerg Clin Immunol. 2009;124(6):S88S93. doi:10.1016/j.jaci.2009.09.050

178. Bacsi A, Choudhury BK, Dharajiya N, Sur S, Boldogh I. Subpollen particles: carriers of allergenic proteins and oxidases. J Allergy Clin Immunol. 2006;118(4):844-850. doi:10.1016/j. jaci.2006.07.006

179. Taylor PE, Flagan RC, Valenta R, Glovsky MM. Release of allergens as respirable aerosols: a link between grass pollen and asthma. J Allergy Clin Immunol. 2002;109(1):51-56. doi:10.1067/ mai.2002.120759

180. Adcock IM, Gilbey T, Gelder CM, Chung KF, Barnes PJ. Glucocorticoid receptor localization in normal and asthmatic lung. Am J Respir Crit Care Med. 1996;154(3):771-782. doi:10.1164/ajrccm.154.3.8810618

181. Lavorini F, Pedersen S, Usmani OS, et al. Dilemmas, confusion, and misconceptions related to small airways directed therapy. Chest. 2017;151(6):1345-1355. doi:10.1016/j.chest.2016.07.035

182. Theron AJ, Steel HC, Tintinger GR, Gravett CM, Anderson R, Feldman C. Cysteinyl leukotriene receptor-1 antagonists as modulators of innate immune cell function. $J$ Immunol Res. 2014;2014:608930. doi:10.1155/2014/608930

183. Holgate ST, Peters-Golden M, Panettieri RA, Henderson WR. Roles of cysteinyl leukotrienes in airway inflammation, smooth muscle function, and remodeling. $J$ Allergy Clin Immunol. 2003;111(1):S18-S34. doi:10.1067/mai.2003.25 
184. Negri J, Early SB, Steinke JW, Borish L. Corticosteroids as inhibitors of cysteinyl leukotriene metabolic and signaling pathways. $J$ Allergy Clin Immunol. 2008;121(5):1232-1237. doi:10.1016/j.jaci.2008.02.007

185. Gyllfors P, Dahlen SE, Kumlin M, Larsson K, Dahlen B. Bronchial responsiveness to leukotriene D4 is resistant to inhaled fluticasone propionate. J Allergy Clin Immunol. 2006;118(1):7883. doi:10.1016/j.jaci.2006.03.040

186. Miligkos M, Bannuru RR, Alkofide H, Kher SR, Schmid CH, Balk EM. Leukotriene-receptor antagonists versus placebo in the treatment of asthma in adults and adolescents: a systematic review and meta-analysis. Ann Intern Med. 2015;163(10):756767. doi:10.7326/M15-1059

187. Zhang HP, Jia CE, Lv Y, Gibson PG, Wang G. Montelukast for prevention and treatment of asthma exacerbations in adults: systematic review and meta-analysis. Allergy Asthma Proc. 2014;35 (4):278-287. doi:10.2500/aap.2014.35.3745

188. Marcello C, Carlo L. Asthma phenotypes: the intriguing selective intervention with Montelukast. Asthma Res Pract. 2016;2:11. doi:10.1186/s40733-016-0026-6

189. Gibson PG, Yang IA, Upham JW, et al. Effect of azithromycin on asthma exacerbations and quality of life in adults with persistent uncontrolled asthma (AMAZES): a randomised, double-blind, placebo-controlled trial. Lancet. 2017;390(10095):659-668. doi:10.1016/S0140-6736(17)31281-3

190. Brusselle GG, Vanderstichele C, Jordens P, et al. Azithromycin for prevention of exacerbations in severe asthma (AZISAST): a multicentre randomised double-blind placebo-controlled trial. Thorax. 2013;68(4):322-329. doi:10.1136/thoraxjnl-2012-202698

191. Shukla SD, Taylor SL, Gibson PG, et al. Add-on azithromycin reduces sputum cytokines in non-eosinophilic asthma: an AMAZES substudy. Thorax. 2021;76:733-736. doi:10.1136/thoraxjnl-2020-216331

192. Niessen NM, Gibson PG, Baines KJ, et al. Sputum TNF markers are increased in neutrophilic and severe asthma and are reduced by azithromycin treatment. Allergy. 2021;76:2090-2101. doi: $10.1111 /$ all.14768

193. Sadeghdoust M, Mirsadraee M, Aligolighasemabadi F, Khakzad MR, Hashemi Attar A, Naghibi S. Effect of azithromycin on bronchial wall thickness in severe persistent asthma: a doubleblind placebo-controlled randomized clinical trial. Respir Med. 2021;185:106494. doi:10.1016/j.rmed.2021.106494

194. Taylor SL, Ivey KL, Gibson PG, Simpson JL, Rogers GB. Airway abundance of Haemophilus influenzae predicts response to azithromycin in adults with persistent uncontrolled asthma. Eur Respir J. 2020;56(4):2000194. doi:10.1183/13993003.001942020

195. Virchow JC. Allergen immunotherapy (AIT) in asthma. Semin Immunol. 2019;46:101334. doi:10.1016/j.smim.2019.101334

196. Virchow JC, Backer V, Kuna P, et al. Efficacy of a house dust mite sublingual allergen immunotherapy tablet in adults with allergic asthma: a randomized clinical trial. JAMA. 2016;315 (16):1715-1725. doi:10.1001/jama.2016.3964

197. Agache I, Lau S, Akdis CA, et al. EAACI guidelines on allergen immunotherapy: house dust mite-driven allergic asthma. Allergy. 2019;74(5):855-873. doi:10.1111/all.13749

198. Anonymous. Xolair. European Medicines Agency; 2018.

199. Anonymous. Nucala. European Medicines Agency; 2018.

200. Anonymous. Cinqaero. European Medicines Agency; 2018.

201. Anonymous. Fasenra. European Medicines Agency; 2018.

202. Anonymous. Dupixent. European Medicines Agency; 2018.

203. Brown T, Jones T, Gove K, et al. Randomised controlled trials in severe asthma: selection by phenotype or stereotype. Eur Respir J. 2018;52(6):1801444. doi:10.1183/13993003.01444-2018
204. Travers J, Marsh S, Williams M, et al. External validity of randomised controlled trials in asthma: to whom do the results of the trials apply? Thorax. 2007;62(3):219-233. doi:10.1136/thx.2006.066837

205. Shamji MH, Valenta R, Jardetzky T, et al. The role of allergenspecific IgE, IgG and IgA in allergic disease. Allergy. 2021;Epub. doi:10.1111/all.14908

206. Arroyave WD, Rabito FA, Carlson JC. The relationship between a specific IgE level and asthma outcomes: results from the 2005-2006 national health and nutrition examination survey. $J$ Allergy Clin Immunol Pract. 2013;1(5):501-508.

207. Naqvi M, Choudhry S, Tsai H-J, et al. Association between IgE levels and asthma severity among African American, Mexican, and Puerto Rican patients with asthma. J Allerg Clin Immunol. 2007;120(1):137-143. doi:10.1016/j.jaci.2007.02.045

208. Guntern P, Eggel A. Past, present, and future of anti-IgE biologics. Allergy. 2020;75(10):2491-2502. doi:10.1111/all.14308

209. Ledford D, Busse W, Trzaskoma B, et al. A randomized multicenter study evaluating Xolair persistence of response after longterm therapy. J Allerg Clin Immunol. 2017;140(1):162-169.e162. doi:10.1016/j.jaci.2016.08.054

210. Normansell R, Walker S, Milan SJ, Walters EH, Nair P. Omalizumab for asthma in adults and children. Cochrane Database Syst Rev. 2014;1:CD003559. doi:10.1002/14651858. CD003559.pub4

211. Bousquet J, Humbert M, Gibson PG, et al. Real-world effectiveness of omalizumab in severe allergic asthma: a meta-analysis of observational studies. J Allergy Clin Immunol Pract. 20219 (7):2702-2714. doi:10.1016/j.jaip.2021.01.011

212. Alhossan A, Lee CS, MacDonald K, Abraham I. "Real-life" effectiveness studies of omalizumab in adult patients with severe allergic asthma: meta-analysis. $J$ Allergy Clin Immunol Pract. 2017;5(5):1362-1370.e1362. doi:10.1016/j. jaip.2017.02.002

213. Berger W, Gupta N, McAlary M, Fowler-Taylor A. Evaluation of long-term safety of the anti-IgE antibody, omalizumab, in children with allergic asthma. Ann Allerg Asthma Immunol. 2003;91 (2):182-188. doi:10.1016/S1081-1206(10)62175-8

214. Di Bona D, Fiorino I, Taurino M, et al. Long-term "real-life" safety of omalizumab in patients with severe uncontrolled asthma: a nine-year study. Respir Med. 2017;130:55-60. doi:10.1016/j.rmed.2017.07.013

215. Long A, Rahmaoui A, Rothman KJ, et al. Incidence of malignancy in patients with moderate-to-severe asthma treated with or without omalizumab. J Allerg Clin Immunol. 2014;134(3):560567.e564. doi:10.1016/j.jaci.2014.02.007

216. Namazy J, Cabana MD, Scheuerle AE, et al. The Xolair Pregnancy Registry (EXPECT): the safety of omalizumab use during pregnancy. J Allerg Clin Immunol. 2015;135(2):407-412. doi:10.1016/j.jaci.2014.08.025

217. Bousquet J, Rabe K, Humbert M, et al. Predicting and evaluating response to omalizumab in patients with severe allergic asthma. Respir Med. 2007;101(7):1483-1492. doi:10.1016/j.rmed.20 07.01 .011

218. Wahn U, Martin C, Freeman P, Blogg M, Jimenez P. Relationship between pretreatment specific IgE and the response to omalizumab therapy. Allergy. 2009;64(12):1780-1787. doi:10.1111/ j.1398-9995.2009.02119.x

219. Casale TB, Chipps BE, Rosén K, et al. Response to omalizumab using patient enrichment criteria from trials of novel biologics in asthma. Allergy. 2018;73(2):490-497. doi:10.1111/all.13302

220. Hanania NA, Wenzel S, Rosén K, et al. Exploring the effects of omalizumab in allergic asthma: an analysis of biomarkers in the EXTRA study. Am J Respir Crit Care Med. 2013;187(8):804811. doi:10.1164/rccm.201208-1414OC 
221. Casale TB, Luskin AT, Busse W, et al. Omalizumab effectiveness by biomarker status in patients with asthma: evidence from PROSPERO, a prospective real-world study. J Allergy Clin Immunol Pract. 2019;7(1):156-164.e151.

222. Humbert M, Taillé C, Mala L, Gros VL, Just J, Molimard M. Omalizumab effectiveness in patients with severe allergic asthma according to blood eosinophil count: the STELLAIR study. Eur Respir J. 2018;51(5):1702523. doi:10.1183/13993003.025232017

223. Tajiri T, Matsumoto H, Gon Y, et al. Utility of serum periostin and free IgE levels in evaluating responsiveness to omalizumab in patients with severe asthma. Allergy. 2016;71(10):1472-1479. doi:10.1111/all.12922

224. Tran TN, Zeiger RS, Peters SP, et al. Overlap of atopic, eosinophilic, and TH2-high asthma phenotypes in a general population with current asthma. Ann Allerg Asthma Immunol. 2016;116 (1):37-42. doi:10.1016/j.anai.2015.10.027

225. Bagnasco D, Menzella F, Caminati M, et al. Efficacy of mepolizumab in patients with previous omalizumab treatment failure: real-life observation. Allergy. 2019;74(12):2539-2541. doi:10.1111/all.13937

226. Carpagnano GE, Pelaia C, D'Amato M, et al. Switching from omalizumab to mepolizumab: real-life experience from Southern Italy. Ther Adv Respir Dis. 2020;14:1-13. doi:10.1177/ 1753466620929231

227. Chapman KR, Albers FC, Chipps B, et al. The clinical benefit of mepolizumab replacing omalizumab in uncontrolled severe eosinophilic asthma. Allergy. 2019;74(9):1716-1726. doi:10.1111/ all. 13850

228. Farne HA, Wilson A, Powell C, Bax L, Milan SJ. Anti-IL5 therapies for asthma. Cochrane Database Syst Rev. 2017;9(9): CD010834. doi:10.1002/14651858.CD010834.pub3

229. Park SW, Kim DJ, Chang HS, et al. Association of interleukin-5 and eotaxin with acute exacerbation of asthma. IAA. 2003;131 (4):283-290.

230. Kay AB, Phipps S, Robinson DS. A role for eosinophils in airway remodelling in asthma. Trends Immunol. 2004;25(9):477-482. doi:10.1016/j.it.2004.07.006

231. Bel EH, Wenzel SE, Thompson PJ, et al. Oral glucocorticoidsparing effect of mepolizumab in eosinophilic asthma. N Engl JMed. 2014;371(13):1189-1197. doi:10.1056/NEJMoa1403291

232. Ortega HG, Liu MC, Pavord ID, et al. Mepolizumab treatment in patients with severe eosinophilic asthma. N Engl J Med. 2014;371 (13):1198-1207. doi:10.1056/NEJMoa1403290

233. Bjermer L, Lemiere C, Maspero J, Weiss S, Zangrilli J, Germinaro M. Reslizumab for inadequately controlled asthma with elevated blood eosinophil levels: a randomized phase 3 study. Chest. 2016;150(4):789-798. doi:10.1016/j.chest.20 16.03 .032

234. Castro M, Zangrilli J, Wechsler ME, et al. Reslizumab for inadequately controlled asthma with elevated blood eosinophil counts: results from two multicentre, parallel, double-blind, randomised, placebo-controlled, phase 3 trials. Lancet Respir Med. 2015;3 (5):355-366. doi:10.1016/S2213-2600(15)00042-9

235. Bleecker ER, FitzGerald JM, Chanez P, et al. Efficacy and safety of benralizumab for patients with severe asthma uncontrolled with high-dosage inhaled corticosteroids and long-acting $\beta 2$-agonists (SIROCCO): a randomised, multicentre, placebo-controlled phase 3 trial. Lancet. 2016;388(10056):2115-2127. doi:10.1016/ S0140-6736(16)31324-1

236. FitzGerald JM, Bleecker ER, Nair P, et al. Benralizumab, an antiinterleukin-5 receptor $\alpha$ monoclonal antibody, as add-on treatment for patients with severe, uncontrolled, eosinophilic asthma (CALIMA): a randomised, double-blind, placebo-controlled phase 3 trial. Lancet. 2016;388(10056):2128-2141. doi:10.1016/ S0140-6736(16)31322-8
237. Nair P, Wenzel S, Rabe KF, et al. Oral glucocorticoid-sparing effect of benralizumab in severe asthma. $N$ Engl JMed. 2017;376 (25):2448-2458. doi:10.1056/NEJMoa1703501

238. Bagnasco D, Caminati M, Menzella F, et al. One year of mepolizumab. Efficacy and safety in real-life in Italy. Pulm Pharmacol Ther. 2019;58(May):101836. doi:10.1016/j.pupt.2019.101836

239. Harvey ES, Langton D, Katelaris C, et al. Mepolizumab effectiveness and identification of super-responders in severe asthma. Eur Respir J. 2020;55(5):1902420. doi:10.1183/13993003.024202019

240. Ibrahim H, O'Sullivan R, Casey D, et al. The effectiveness of Reslizumab in severe asthma treatment: a real-world experience. Respir Res. 2019;20(1):289. doi:10.1186/s12931-019-1251-3

241. Kavanagh JE, D' Ancona G, Elstad M, et al. Real-world effectiveness and the characteristics of a "super-responder" to mepolizumab in severe eosinophilic asthma. Chest. 2020;158(2):491500. doi:10.1016/j.chest.2020.03.042

242. Kavanagh JE, Hearn AP, D’ Ancona G, et al. Benralizumab after sub-optimal response to mepolizumab in severe eosinophilic asthma. Allergy. 2021;76(6):1890-1893. doi:10.1111/all.14693

243. Menzella F, Bonavia M, Bonini M, et al. Real-world experience with benralizumab in patients with severe eosinophilic asthma: a case series. JAA. 2021;14:149-161. doi:10.2147/JAA.S295676

244. Padilla-Galo A, Levy-Abitbol R, Olveira C, et al. Real-life experience with benralizumab during 6 months. BMC Pulm Med. 2020;20(1):184. doi:10.1186/s12890-020-01220-9

245. Pelaia C, Busceti MT, Vatrella A, et al. Real-life rapidity of benralizumab effects in patients with severe allergic eosinophilic asthma: assessment of blood eosinophils, symptom control, lung function and oral corticosteroid intake after the first drug dose. Pulm Pharmacol Ther. 2019;58:101830. doi:10.1016/j. pupt.2019.101830

246. Pelaia C, Crimi C, Pelaia G, et al. Real-life evaluation of mepolizumab efficacy in patients with severe eosinophilic asthma, according to atopic trait and allergic phenotype. Clin Exp Allerg. 2020;50(7):780-788. doi:10.1111/cea.13613

247. Schleich F, Graff S, Nekoee H, et al. Real-world experience with mepolizumab: does it deliver what it has promised? Clin Exp Allerg. 2020;50(6):687-695. doi:10.1111/cea.13601

248. Wechsler ME, Akuthota P, Jayne D, et al. Mepolizumab or placebo for eosinophilic granulomatosis with polyangiitis. $N$ Engl JMed. 2017;376(20):1921-1932. doi:10.1056/NEJMoa1702079

249. Mukherjee M, Bakakos P, Loukides S. New paradigm in asthma management: switching between biologics! Allergy. 2020;75 (4):743-745. doi:10.1111/all.14038

250. Pérez de Llano LA, Cosío BG, Domingo C, et al. Efficacy and safety of reslizumab in patients with severe asthma with inadequate response to omalizumab: a multicenter, open-label pilot study. J Allergy Clin Immunol. 2019;7(7):2277-2283.e2272.

251. Burke H, Davis J, Evans S, Flower L, Tan A, Kurukulaaratchy RJ. A multidisciplinary team case management approach reduces the burden of frequent asthma admissions. ERJ Open Res. 2016;2 (3):00039-2016. doi:10.1183/23120541.00039-2016

252. Mukherjee M, Aleman Paramo F, Kjarsgaard M, et al. Weightadjusted intravenous reslizumab in severe asthma with inadequate response to fixed-dose subcutaneous mepolizumab. Am J Respir Crit Care Med. 2017;197(1):38-46. doi:10.1164/rccm.201707$1323 \mathrm{OC}$

253. Manetz S, Maric I, Brown T, et al. Successful pregnancy in the setting of eosinophil depletion by benralizumab. J Allergy Clin Immunol Pract. 2021;9(3):1405-1407.e1403.

254. Saco T, Tabatabaian F. Breathing for two: a case of severe eosinophilic asthma during pregnancy treated with benralizumab. Ann Allerg Asthma Immunol. 2018;121(5):S92. doi:10.1016/j. anai.2018.09.300 
255. Albers FC, Licskai C, Chanez P, et al. Baseline blood eosinophil count as a predictor of treatment response to the licensed dose of mepolizumab in severe eosinophilic asthma. Respir Med. 2019;159:105806. doi:10.1016/j.rmed.2019.105806

256. Busse W, Chupp G, Nagase H, et al. Anti-IL-5 treatments in patients with severe asthma by blood eosinophil thresholds: indirect treatment comparison. J Allerg Clin Immunol. 2019;143 (1):190-200.e120. doi:10.1016/j.jaci.2018.08.031

257. Ortega HG, Yancey SW, Mayer B, et al. Severe eosinophilic asthma treated with mepolizumab stratified by baseline eosinophil thresholds: a secondary analysis of the DREAM and MENSA studies. Lancet Respir Med. 2016;4(7):549-556. doi:10.1016/ S2213-2600(16)30031-5

258. Kavanagh JE, Hearn AP, Dhariwal J, et al. Real world effectiveness of benralizumab in severe eosinophilic asthma. Chest. 2020;158:491-500.

259. Bagnasco D, Massolo A, Bonavia M, et al. The importance of being not significant: blood eosinophils and clinical responses do not correlate in severe asthma patients treated with mepolizumab in real life. Allergy. 2020;75(6):1460-1463. doi:10.1111/all.14135

260. Drick N, Seeliger B, Welte T, Fuge J, Suhling H. Anti-IL-5 therapy in patients with severe eosinophilic asthma - clinical efficacy and possible criteria for treatment response. BMC Pulm Med. 2018;18(1):119. doi:10.1186/s12890-018-0689-2

261. Agache I, Beltran J, Akdis C, et al. Efficacy and safety of treatment with biologicals (benralizumab, dupilumab, mepolizumab, omalizumab and reslizumab) for severe eosinophilic asthma. A systematic review for the EAACI guidelines - recommendations on the use of biologicals in severe asthma. Allergy. 2020;75 (5):1023-1042. doi:10.1111/all.14221

262. Rabe KF, Nair P, Brusselle G, et al. Efficacy and safety of dupilumab in glucocorticoid-dependent severe asthma. $N$ Engl JMed. 2018;378:2475-2485. doi:10.1056/NEJMoa1804093

263. Wenzel S, Castro M, Corren J, et al. Dupilumab efficacy and safety in adults with uncontrolled persistent asthma despite use of medium-to-high-dose inhaled corticosteroids plus a long-acting $\beta 2$ agonist: a randomised double-blind placebo-controlled pivotal phase 2b dose-ranging trial. Lancet. 2016;388(10039):31-44. doi:10.1016/S0140-6736(16)30307-5

264. Corren J, Castro M, O'Riordan T, et al. Dupilumab efficacy in patients with uncontrolled, moderate-to-severe allergic asthma. $J$ Allergy Clin Immunol Pract. 2020;8(2):516-526.

265. Dupin C, Belhadi D, Guilleminault L, et al. Effectiveness and safety of dupilumab for the treatment of severe asthma in a reallife French multi-centre adult cohort. Clin Exp Allerg. 2020;50 (7):789-798. doi:10.1111/cea.13614

266. Campisi R, Crimi C, Nolasco S, et al. Real-world experience with dupilumab in severe asthma: one-year data from an Italian named patient program. JAA. 2021;14:575-583. doi:10.2147/JAA. S312123

267. Nowsheen S, Darveaux JI. Real-world efficacy and safety of dupilumab use in the treatment of asthma. Ann Allerg Asthma Immunol. 2021;127:147-149. doi:10.1016/j.anai.2021.04.011

268. Renner A, Marth K, Patocka K, Idzko M, Pohl W. Dupilumab rapidly improves asthma control in predominantly anti-IL5/IL5R pretreated Austrian real-life severe asthmatics. Immun Inflam Dis. 2021;9(3):624-627. doi:10.1002/iid3.434

269. Mümmler C, Munker D, Barnikel M, et al. Dupilumab improves asthma control and lung function in patients with insufficient outcome during previous antibody therapy. J Allergy Clin Immunol. 2021;9(3):1177-1185.e1174.
270. Bosma AL, Gerbens LA, Middelkamp-Hup MA, Spuls PI. Paternal and maternal use of dupilumab in patients with atopic dermatitis: a case series. Clin Exp Dermatol. 202146(6):10891092. doi:10.1111/ced.14725

271. Kage P, Simon JC, Treudler R. A case of atopic eczema treated safely with dupilumab during pregnancy and lactation. J Eur Acad Dermatol Venereol. 2020;34(6):e256-e257. doi:10.1111/ jdv. 16235

272. Mian M, Dunlap R, Simpson E. Dupilumab for the treatment of severe atopic dermatitis in a pregnant patient: a case report. JAAD Case Rep. 2020;6(10):1051-1052. doi:10.1016/j.jdcr.2020.08.001

273. Regeneron P. Registry of Asthma Patients Initiating DUPIXENT® (RAPID). 2021. 05 June, 2021. NCT04287621.

274. Guntur VP, Manka LA, Denson JL, et al. Benralizumab as a steroid-sparing treatment option in eosinophilic granulomatosis with polyangiitis. J Allergy Clin Immunol. 2021;9(3):1186-1193. e1181.

275. Han JK, Bachert C, Fokkens W, et al. Mepolizumab for chronic rhinosinusitis with nasal polyps (SYNAPSE): a randomised, double-blind, placebo-controlled, phase 3 trial. Lancet Respir Med. 2021;Epub. doi:10.1016/S2213-2600(21)00097-7

276. Takabayashi T, Asaka D, Okamoto Y, et al. A phase II, multicenter, randomized, placebo-controlled study of benralizumab, a humanized anti-IL-5R alpha monoclonal antibody, in patients with eosinophilic chronic rhinosinusitis. Am J Rhinol Allerg. 2021;Epub. doi:10.1177/19458924211009429

277. Tversky J, Lane AP, Azar A. Benralizumab effect on severe chronic rhinosinusitis with nasal polyps (CRSwNP): a randomized double-blind placebo-controlled trial. Clin Exp Allerg. 2021;51(6):836-844. doi:10.1111/cea.13852

278. Assa'ad AH, Gupta SK, Collins MH, et al. An antibody against IL-5 reduces numbers of esophageal intraepithelial eosinophils in children with eosinophilic esophagitis. Gastroenterology. 2011;141(5):1593-1604. doi:10.1053/j.gastro.2011.07.044

279. Menzies-Gow A, Corren J, Bourdin A, et al. Tezepelumab in adults and adolescents with severe, uncontrolled asthma. $N$ Engl JMed. 2021;384(19):1800-1809. doi:10.1056/NEJMoa2034975

280. Peters MC, Wenzel SE. Intersection of biology and therapeutics: type 2 targeted therapeutics for adult asthma. Lancet. 2020;395 (10221):371-383. doi:10.1016/S0140-6736(19)33005-3

281. Ziegler SF, Roan F, Bell BD, Stoklasek TA, Kitajima M, Han H. The biology of thymic stromal lymphopoietin (TSLP). Adv Pharmacol. 2013;66:129-155.

282. Porsbjerg CM, Sverrild A, Lloyd CM, Menzies-Gow AN, Bel EH. Anti-alarmins in asthma: targeting the airway epithelium with next-generation biologics. Eur Respir J. 2020;56 (5):2000260. doi:10.1183/13993003.00260-2020

283. Brightling C, Kulkarni S, Lambrecht BN, Sandham D, Weiss M, Altman P. The pharmacology of the prostaglandin D2 receptor 2 (DP2) receptor antagonist, fevipiprant. Pulm Pharmacol Ther. 2021;68:102030. doi:10.1016/j.pupt.2021.102030

284. Prussin C, Panettieri RA, Bozik ME, Archibald DG, Mather JL, Siddiqui S. Oral dexpramipexole efficacy in lowering blood eosinophils in patients with moderate to severe uncontrolled eosinophilic asthma: study design and baseline data from the AS201 phase 2 trial. Am J Respir Crit Care Med. 2021;203: A 1359. 


\section{Publish your work in this journal}

The Journal of Inflammation Research is an international, peerreviewed open-access journal that welcomes laboratory and clinical findings on the molecular basis, cell biology and pharmacology of inflammation including original research, reviews, symposium reports, hypothesis formation and commentaries on: acute/chronic inflammation; mediators of inflammation; cellular processes; molecular mechanisms; pharmacology and novel anti-inflammatory drugs; clinical conditions involving inflammation. The manuscript management system is completely online and includes a very quick and fair peerreview system. Visit http://www.dovepress.com/testimonials.php to read real quotes from published authors. 